\title{
The Polyadenosine RNA Binding Protein ZC3H14 is Required in Mice for Proper Dendritic Spine Density
}

Stephanie K. Jones ${ }^{1,2}$, Jennifer Rha ${ }^{1,3}$, Sarah Kim ${ }^{1}$, Kevin J. Morris ${ }^{1,3}$, Omotola F. Omotade ${ }^{3,4}$, Kenneth H. Moberg ${ }^{3}$, Kenneth R. Myers ${ }^{3}+$ and Anita H. Corbett ${ }^{1}+$

${ }^{1}$ Department of Biology, Emory University,

Graduate Programs in ${ }^{2}$ Genetics and Molecular Biology and ${ }^{3}$ Biochemistry, Cell, and Developmental Biology and ${ }^{4}$ Department of Cell Biology, Emory University School of Medicine, Atlanta, GA 30322 USA

\section{For Correspondence:}

+Co-corresponding authors

\author{
Anita H. Corbett \\ Department of Biology \\ Emory University \\ 1510 Clifton Road, NE \\ Rollins Research Center, Room 1021 \\ Atlanta, GA 30322 \\ Phone: 404-727-4546 \\ Email: acorbe2@emory.edu \\ and \\ Kenneth R. Myers \\ Department of Cell Biology \\ Emory University School of Medicine \\ 615 Michael Street \\ Whitehead Biomedical Research Building, Room 555 \\ Atlanta, GA 30322 \\ Phone: 404-727-4787 \\ Email:kennethmyers@emory.edu
}

Abbreviated Title: ZC3H14 is Required for Proper Dendritic Spine Density

Keywords: ZC3H14, polyadenosine RNA binding protein, intellectual disability, dendritic spine

Conflict of Interest: The authors declare no competing financial interests

Acknowledgements: Financial support as follows - NIH F31 HD070735 (JR), F31 NS092437 (OFO) and NIH MH107305, AG054206 and GM058728 (AHC and KHM). Research reported in this publication was supported in part by the Emory University Integrated Cellular Imaging Microscopy Core of the Emory Neuroscience NINDS Core Facilities grant, 5P30NS055077. The content is solely the responsibility of the authors and does not necessarily reflect the official views of the National Institute of Health. We thank Drs. James Zheng, Shannon Gourley, Jinnah Hyder, and Paul Garcia for helpful discussions and advice as well as members of the Moberg, Zheng, and Corbett laboratories for their support. 


\section{Abstract}

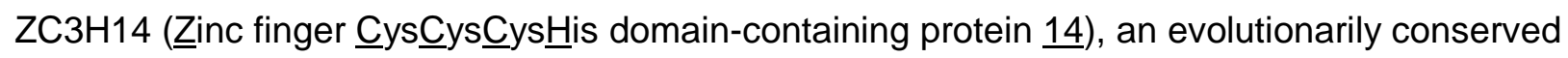
member of a class of tandem zinc finger $(\mathrm{CCCH})$ polyadenosine (polyA) RNA binding proteins, is associated with a form of heritable, nonsyndromic autosomal recessive intellectual disability. Previous studies of a loss of function mouse model, Zc3h14 ${ }^{\Delta e \times 13 / \Delta e x 13}$, provide evidence that ZC3H14 is essential for proper brain function, specifically for working memory. To expand on these findings, we analyzed the dendrites and dendritic spines of hippocampal neurons from Zc3h14 ${ }^{\Delta e \times 13 / \Delta e x 13}$ mice, both in situ and in vitro. These studies reveal that loss of $\mathrm{ZC} 3 \mathrm{H} 14$ is associated with a decrease in total spine density in hippocampal neurons in vitro as well as in the dentate gyrus of 5-month old mice analyzed in situ. This reduction in spine density in vitro results from a decrease in the number of mushroom-shaped spines, which is rescued by exogenous expression of $\mathrm{ZC} 3 \mathrm{H} 14$. We next performed biochemical analyses of synaptosomes prepared from whole wild-type and $Z c 3 h 14^{\Delta e \times 13 / \Delta e x 13}$ mouse brains to determine if there are changes in steady state levels of postsynaptic proteins upon loss of $\mathrm{ZC} 3 \mathrm{H} 14$. We found that $\mathrm{ZC} 3 \mathrm{H} 14$ is present within synaptosomes and that a crucial postsynaptic protein, CaMKIla, is significantly increased in these synaptosomal fractions upon loss of $\mathrm{ZC} 3 \mathrm{H} 14$. Together, these results demonstrate that $\mathrm{ZC} 3 \mathrm{H} 14$ is necessary for proper dendritic spine density in cultured hippocampal neurons and in some regions of the mouse brain. These findings provide insight into how a ubiquitously expressed RNA binding protein leads to neuronal-specific defects that result in brain dysfunction. 


\section{Introduction}

Brain development requires the formation of complex neural circuits where individual neurons communicate with one another at sites of connections termed synapses (Sheng \& Hoogenraad, 2007; Yuste, 2011). The majority of excitatory synapses are positioned at dendritic spines, small protrusions found on the dendritic branches of neurons (J. N. Bourne \& Harris, 2008; Segal, 2005). These spines function as discrete biochemical signaling centers and are one of the primary sites of information processing in the brain (Adrian et al., 2014; Y. Chen \& Sabatini, 2012; Svoboda, Tank, \& Denk, 1996). During development, spines are generally thought to transition from thin filopodia through a maturation process that involves interim spine types into mature mushroom-shaped spines (Berry \& Nedivi, 2017). These spines remain dynamic even in mature neurons to support synaptic plasticity (De Roo, Klauser, Garcia, Poglia, \& Muller, 2008). The size of the spine head positively correlates with the number of glutamate receptors at the postsynaptic surface (Borczyk, Sliwinska, Caly, Bernas, \& Radwanska, 2019; Noguchi, Matsuzaki, Ellis-Davies, \& Kasai, 2005; Nusser et al., 1998). Thus, the morphology of dendritic spines is tightly linked to synaptic strength. Consequently, defects in dendrite spine morphology are associated with numerous neurological disorders, including fragile X syndrome, autism, and epilepsy (Fiala, Spacek, \& Harris, 2002; Forrest, Parnell, \& Penzes, 2018; Newey, Velamoor, Govek, \& Van Aelst, 2005; Phillips \& Pozzo-Miller, 2015).

Because dendrites and axons extend far away from the neuronal cell body, tight regulation of gene expression is essential for normal neuronal development and synaptic plasticity. Once exported from the nucleus, mRNAs are transported to local sites for translation, allowing new proteins to be rapidly synthesized at or near individual synapses in response to stimuli such as synaptic activity (Besse \& Ephrussi, 2008; Holt \& Schuman, 2013). This translation in dendrites provides a mechanism for maintaining and modifying the local proteome that is more rapid and efficient than synthesizing proteins in the cell body and transporting them to a specific site (Glock, Heumuller, \& Schuman, 2017). Numerous studies have directly linked synaptic plasticity to local translation and have identified specific subsets of mRNAs that localize preferentially to dendrites and dendritic spines (Cajigas et al., 2012; 
Jones et al. page 4

Huber, Kayser, \& Bear, 2000; Kang \& Schuman, 1996; Poon, Choi, Jamieson, Geschwind, \& Martin, 2006). A large number of RNA binding proteins mediate the many events that comprise posttranscriptional gene regulation, including events that occur in the nucleus prior to export to the cytoplasm (Scherrer, 2018), such as splicing, editing, and polyadenylation and the cytoplasmic events that contribute to local translation (Glock et al., 2017). Numerous studies have linked RNA binding proteins to synaptic plasticity, learning and memory, and neurological disease (Cooper, Wan, \& Dreyfuss, 2009; Kapur \& Ackerman, 2018; Liu-Yesucevitz et al., 2011; Scheper, van der Knaap, \& Proud, 2007; M. P. Thelen \& Kye, 2019; Wang et al., 2016).

Many of the RNA binding proteins linked to neurological disease play multiple roles in posttranscriptional regulation of gene expression (Maximilian Paul Thelen \& Kye, 2020). ZC3H14 (Zinc Finger $\mathrm{CCCH}$-Type Containing 14) is an evolutionarily conserved, ubiquitously expressed polyadenosine RNA-binding protein (Leung et al., 2009). Mutations in the $Z C 3 H 14$ gene cause an autosomal-recessive, non-syndromic form of intellectual disability (AI-Nabhani et al., 2018; S. Kelly et al., 2012; Pak et al., 2011). Studies examining the essential budding yeast orthologue, Nab2, have identified roles in regulating poly $(\mathrm{A})$ tail length, RNA splicing, and mRNA decay (Anderson, Wilson, Datar, \& Swanson, 1993; Hector et al., 2002; Marfatia, Crafton, Green, \& Corbett, 2003; Schmid et al., 2015; Soucek et al., 2016). The Drosophila orthologue of ZC3H14, Nab2, also plays a role in poly(A) tail length control (S. M. Kelly et al., 2016; S. M. Kelly et al., 2014; Pak et al., 2011). Studies in mammalian cells show that regulation of poly $(A)$ tail length is a conserved function of ZC3H14 (S. M. Kelly et al., 2014). Loss of Nab2 function in yeast or flies is lethal (Anderson et al., 1993; Pak et al., 2011) and mutant flies exhibit defects in locomotor behavior as well as abnormal brain morphology (S. M. Kelly et al., 2016; Pak et al., 2011). Work exploiting the Drosophila system showed that Nab2 function is essential in neurons as phenotypes observed in flies lacking Nab2 can be rescued by neuronal-specific expression of Nab2 (Pak et al., 2011). These studies provide insight into why mutations in the ubiquitously expressed $\mathrm{ZC} 3 \mathrm{H} 14$ gene cause neurological deficits. 
Multiple isoforms of $\mathrm{ZC} 3 \mathrm{H} 14$ are produced in mammals through alternative splicing (See Fig. 3C) (Leung et al., 2009). All four ZC3H14 isoforms include the essential zinc finger RNA-binding domain (S. M. Kelly et al., 2010); however, isoforms 1-3 contain an N-terminal Proline-Tryptophan-Isoleucine (PWI)-like domain as well as a predicted nuclear localization signal, while isoform 4 contains an alternative first exon. $\mathrm{ZC} 3 \mathrm{H} 14$ isoforms 1-3 are ubiquitously expressed, whereas isoform 4 is expressed primarily in testis (Leung et al., 2009). While ZC3H14 isoforms 1-3 are primarily localized to nuclear speckles (Guthrie, Greenup, Leverenz, \& Kraemer, 2011; Leung et al., 2009), analysis of cultured primary rat hippocampal neurons shows that $\mathrm{ZC} 3 \mathrm{H} 14$ is found in both the nucleus and in neuronal processes (Bienkowski et al., 2017). Studies of cultured primary Drosophila neurons reveal that Nab2 is present within puncta in neurites, associated with both ribonucleoprotein complexes and polyribosomes (Bienkowski et al., 2017). In addition, cell fractionation assays from whole mouse brain reveal a cytoplasmic pool of $\mathrm{ZC} 3 \mathrm{H} 14$, although the majority of the protein is found in the nucleus (Morris \& Corbett, 2018). These observations regarding the localization of $\mathrm{ZC} 3 \mathrm{H} 14$ are consistent with studies of the budding yeast Nab2 protein, which show that Nab2 is a shuttling RNA binding protein that can exit the nucleus in an poly(A) RNA-dependent manner (Green et al., 2002). This dynamic localization of $\mathrm{Nab2/ZC3H14,} \mathrm{means} \mathrm{that} \mathrm{ZC} 3 \mathrm{H} 14$ could regulate target RNAs in the nucleus and/or the cytoplasm.

To explore the function of $\mathrm{ZC} 3 \mathrm{H} 14$ in mammals, a Zc3h14 mutant mouse was generated (Rha et al., 2017). This mouse model removes exon 13 of Zc3h14, which is the first common exon present in all Zc3h14 splice variants. This exon encodes part of the essential zinc finger RNA binding domain and thus no functional ZC3H14 protein is produced in homozygous Zc3h14 $4^{\operatorname{sex} 13 / \Delta e \times 13}$ mice (Marfatia et al., 2003; Rha et al., 2017). These studies revealed that the ZC3H14 protein is not essential in mice; however Zc3h14 $4^{\operatorname{sex} 13 / \Delta e \times 13}$ mice show defects in working memory, further supporting a role for ZC3H14 in normal brain function (Rha et al., 2017). Proteomic analysis comparing hippocampi from

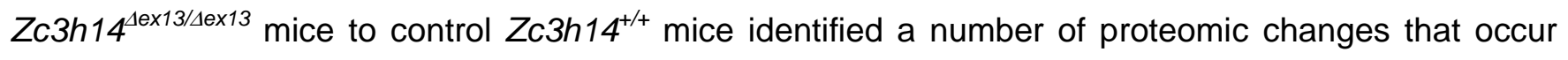
upon the loss of $\mathrm{ZC} 3 \mathrm{H} 14$, including many changes in proteins with key synaptic functions. Mice lacking ZC3H14 show an increase in the steady-state levels of CaMKIla, a protein kinase that plays a key role 
in learning and memory (Coultrap \& Bayer, 2012; Coultrap et al., 2014; Herring \& Nicoll, 2016; Kim \& Hayashi, 2014; Rha et al., 2017). Furthermore, the ZC3H14 protein binds to CaMKIla mRNA (Rha et al., 2017). Complementary work in Drosophila shows that Nab2 associates with CaMKII mRNA and represses a CaMKII translational reporter (Bienkowski et al., 2017). Taken together, these studies suggest a role for $\mathrm{ZC} 3 \mathrm{H} 14$ in regulating expression of CaMKII. As CaMKIla plays key roles in regulating dendritic spine morphology (Fukunaga, Shioda, \& Miyamoto, 2009), these results suggest that the loss of $\mathrm{ZC} 3 \mathrm{H} 14$ could alter dendritic spine development; however, whether $\mathrm{ZC} 3 \mathrm{H} 14$ is required for proper dendritic spine density or morphology has not yet been examined.

In this study, we analyze the $Z c 3 h 14^{4 e \times 13 / \Delta e \times 13}$ mouse model and find that loss of $Z \mathrm{C} 3 \mathrm{H} 14$ decreases dendritic spine density both in situ and in vitro. This decrease in spine density corresponds

to a reduction in the number of mushroom-shaped spines. Conversely, overexpression of $\mathrm{ZC} 3 \mathrm{H} 14$ increases the density of spines, in a $\mathrm{ZC} 3 \mathrm{H} 14$ isoform-specific manner. Finally, $\mathrm{ZC} 3 \mathrm{H} 14$ is present in synaptosomes and the loss of $\mathrm{ZC} 3 \mathrm{H} 14$ leads to an increase in the steady-state level of CaMKIla in synaptosomes. Together, our results demonstrate that $\mathrm{ZC} 3 \mathrm{H} 14$ is required for proper dendritic spine density and suggest a role for $\mathrm{ZC} 3 \mathrm{H} 14$ in regulating dendritic spine morphogenesis.

\section{Material and Methods}

\section{Mice}

Mouse lines $Z c 3 h 14^{+/+}$and $Z c 3 h 14^{\Delta e \times 13 / \Delta e \times 13}$ were bred and maintained as previously described (Rha et al., 2017).We previously generated heterozygously floxed Zc3h14 exon 13 mice $\left(Z c 3 h 14^{F /+}\right)$ by mating adult male chimeras to C57BL/6N wild-type female mice (The Jackson Laboratory). Offspring generated from this mating were then mated to generate homozygously floxed mutant mice $\left(Z c 3 h 14^{F / F}\right)$. Ella-Cre mice (purchased from The Jackson Laboratory, Stock \#003724, mixed C57BL/6J and C57BL/6N genetic background) which express Cre-recombinase active at the zygotic stage (Lakso et al., 1996), were mated to homozygously floxed Zc3h14 exon $13\left(Z c 3 h 14^{F / F}\right)$ mice for 3-4 generations to 
generate a germline-transmissible Zc3h14 allele lacking exon $13\left(Z c 3 h 14^{\Delta e \times 13 / 4 e \times 13}\right)$. These mice with confirmed proper recombination were mated to wild-type C57BL/6 mice (purchased from The Jackson Laboratory) to breed out the Ella-Cre allele. Ella-Cre-negative, Zc3h14 ${ }^{\text {ex } 13 /+}$ were mated to generate Zc3h14 $4^{\operatorname{sex} 13 / 4 \operatorname{ex} 13}$ mutant homozygous mice for at least four generations.

Control $Z c 3 h 14^{+/+}$were maintained in the colony as control counterparts from the heterozygous

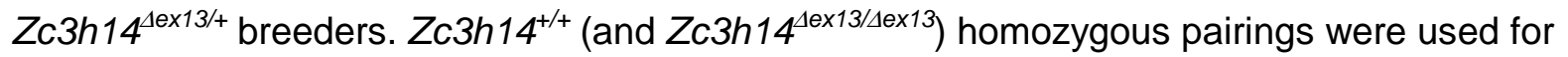
experiments, and homozygous off-spring were routinely cross-bred to minimize genetic drift between Zc3h $14^{+/+}$and Zc3h14 ${ }^{4 e \times 13 / 4 e \times 13}$ mice.

All procedures involving mice were performed in accordance with the NIH guidelines for use and care of live animals and were approved by the Emory University Institutional Animal Care and Use Committee.

\section{Golgi Staining}

Male mice were sacrificed and whole brains isolated at either postnatal day 7 (P7) (six (6)

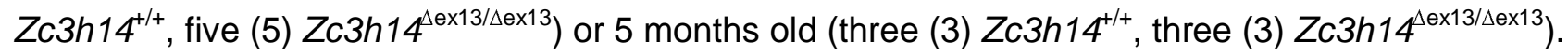
Whole brains were subsequently processed using the FD Rapid GolgiStain® Kit protocol (Du, 2019; Garcia-Lopez, Garcia-Marin, \& Freire, 2007; Ramón-Moliner, 1970). After complete penetration of the Golgi stain solutions, brains were dip frozen in a block of optimal cutting temperature (OCT) compound and sliced coronally on a Leica CM1850 cryostat at a slice thickness of $240 \mu$ m onto gelatin-coated slides. Slides were stained and counterstained with cresyl violet, cleared, and mounted with Permount as according to the FD Rapid Golgi stain Kit protocol.

Images of dendrites from dentate gyrus granule cells were captured using an Olympus BX51 brightfield microscope at 100x. Cells were required to have at least one unbroken dendrite at least 75 $\mu \mathrm{m}$ long and originating from the soma to be considered for imaging. The fine focus was manually adjusted every $\sim 0.5 \mu \mathrm{m}$ to capture the whole image area, with stacking and compositing performed in Adobe Photoshop CS5. Dendritic spines were manually called and counted. Experimenters were 
blinded to genotype while both imaging and counting. Significance was calculated using an unpaired $t$ test.

\section{Primary hippocampal neuronal culture}

Dissociated hippocampal neurons were cultured from embryonic day 17.5 (E17.5) mouse embryos of both sexes from a single litter. Briefly, brains were removed from embryos, and then hippocampi were dissected in ice cold Hank's Balanced Salt Solution (HBSS). Hippocampi were pooled together and dissociated using trypsin for 12 minutes, then triturated and plated on $25 \mathrm{~mm}$ coverslips coated overnight with $100 \mu \mathrm{g} / \mathrm{ml}$ poly-L-lysine (Sigma). Neurons were plated at a density of approximately 350,000 cells per $35 \mathrm{~mm}$ dish. Cells were maintained in Neurobasal medium (ThermoFisher) supplemented with B-27 (ThermoFisher), penicillin/streptomycin, and GlutaMax (Invitrogen). Cells were fed once a week by replacing half of the medium with fresh growth medium.

\section{Transfection of hippocampal neurons}

Hippocampal neurons were transfected at 11 days in vitro (DIV 11) using Calphos calcium phosphate transfection reagent (Takara) according to manufacturer's protocol. The following DNA plasmids were used: GFP-ZC3H14-Isoform 1 and GFP-ZC3H14-Isoform 3 (Leung et al., 2009) , LifeAct-mRuby (Riedl et al., 2008) (provided by Dr. Gary Bassell, Emory University), and eGFP-N1 (GFP). All DNA constructs were prepared using Endotoxin-free Maxi Prep kits (Qiagen).

\section{Immunofluorescence microscopy}

Hippocampal neurons were fixed at either DIV 12 or DIV 19 using freshly prepared $4 \%$ paraformaldehyde (PFA) and 4\% sucrose in phosphate-buffered saline (PBS) for 15 minutes at room temperature. Neurons were washed in PBS, then blocked and permeabilized in PBS supplemented with $5 \%$ normal goat serum, and $0.2 \%$ Triton $X-100$ for 1 hour at room temperature. Cells were incubated with primary antibodies (rabbit anti-RFP (600-401-279; Rockland; 1:1000) and mouse antiGFP (A-11120; Invitrogen; 1;2000) for 1 hour, then with Alexa Fluor (Alexa-488 or Alexa-546; 1:750; ThermoFisher Scientific) secondary antibodies for 1 hour, and finally mounted with Fluoromount-G 
(Southern Biotech). All samples were blinded prior to image acquisition and their identities revealed after image analysis was completed. Dendritic arbors were imaged using an epifluorescent Nikon Eclipse Ti inverted microscope with a 20x objective (Plan Fluor, $0.5 \mathrm{NA}$ ). Analysis, including tracing and Sholl analysis, was carried out using the ImageJ Simple Neurite Tracer plugin (Longair, Baker, \& Armstrong, 2011). Dendritic spines were imaged as Z-stacks comprised of 21 optical sections $(0.2 \mu \mathrm{m}$ step-size) using a Nikon C2 laser-scanning confocal system with an inverted Nikon Ti2 microscope (60x Plan Apo objective, 1.4 NA). For display purposes, 2D images were generated from maximum intensity projections of Z-stacks. For image analysis, dendrite and spine volumes were reconstructed from Z-stacks using the Filament Tracer module in Imaris (Bitplane). Spine heads were manually seeded prior to spine volume reconstruction. Density and classification of dendritic spines were determined using automated measurements produced from the Filament Tracer module. For each neuron imaged, spines were analyzed from four separate secondary or tertiary dendritic branches (a minimum of $25 \mu \mathrm{m}$ long) at least $50 \mu \mathrm{m}$ away from the soma. Spines were classified as either stubby, mushroom, or thin, following parameters previously described (Swanger, Yao, Gross, \& Bassell, 2011). Briefly, stubby spines are defined as having a length $<1 \mu \mathrm{m}$ and a head/neck width ratio $<1.5$; thin spines are defined as having a length 1-5 $\mu \mathrm{m}$ and a head/neck width ratio $<1.5$; mushroom spines are defined as having a length $<5 \mu \mathrm{m}$ and a head/neck width ratio $>1.5$.

\section{Synaptosomal Fractionation}

Mice were sacrificed and whole brains isolated at postnatal day 0 (P0). Brains were immediately frozen on dry ice, and stored at $-80^{\circ} \mathrm{C}$. We employed validated PCR primers to confirm the genotype of these P0 brains (Rha et al., 2017). These whole brains were homogenized in Thermo Scientific SynPER Synaptic Protein Extraction Reagent with EDTA-free protease inhibitor, using a Dounce tissue

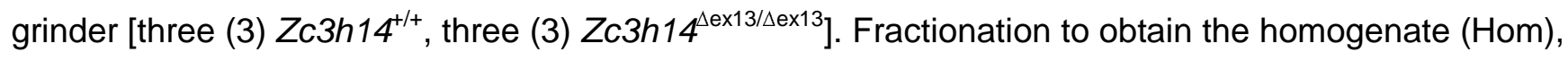
cytosol (Cyt), and synaptosome (Syn) fractions was performed as described in the Thermo Scientific Syn-PER Synaptic Protein Extraction Reagent protocol. 
Jones et al.

page 10

\section{Immunoblotting}

Samples from the synaptosomal fractionation were resolved by SDS-PAGE and transferred to a $0.2 \mu \mathrm{m}$ nitrocellulose membrane (Bio-Rad Laboratories). After blocking non-specific binding with 5\% nonfat milk in 1X TBST (Tris-Buffered Saline, 0.1\% Tween 20) solution, the membranes were incubated with primary antibody [anti-ZC3H14 (Leung et al., 2009), CaMKIla (Thermo Fisher 13-7300), PSD-95 (Sigma-Aldrich MAB1598), Synaptophysin (Sigma-Aldrich MAB5258)], followed by incubation with the appropriate horseradish peroxidase (HRP)-conjugated secondary IgG antibody (Jackson ImmunoResearch). Total protein was visualized by Ponceau staining. Quantification of chemiluminescence and Ponceau staining was carried out in ImageJ, with significance calculated with an unpaired $t$ test.

\section{Results}

\section{Spine density in the dentate gyrus is decreased in adult mice upon loss of ZC3H14}

To assess whether the loss of $\mathrm{ZC} 3 \mathrm{H} 14$ alters dendritic spine density, we performed Golgi staining (Du, 2019; Ramón-Moliner, 1970) on Zc3h14 ${ }^{+/+}(+/+)$and Zc3h14 $4^{\Delta e \times 13 / \Delta e x 13}(\Delta 13 / \Delta 13)$ whole male mouse brains at postnatal day 7 (P7) and 5 months (Fig. 1). Samples were prepared as described in Materials and Methods and dentate gyrus granule neurons were imaged by brightfield microscopy (Fig. 1A). We did not observe any obvious qualitative difference in dendritic spine density comparing granule cells from Zc3h14 ${ }^{+/+}$and Zc3h14 $4^{\Delta e x 13 / \Delta e x 13}$ mice at P7. Quantification of dendritic spine density (Fig. 1B) reveals no statistically significant difference in spine density upon the loss of ZC3H14 as assessed at this time point ( $p>0.05 ;+/+n=43$ neurons, 6 mice; $\Delta 13 / \Delta 13 n=35$ neurons, 5 mice). However, dentate

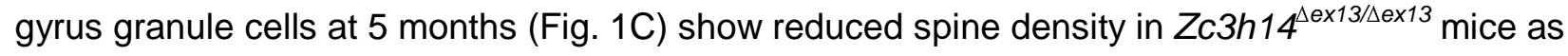
compared to $Z c 3 h 14^{+/+}$mice. Indeed, quantification of the samples from 5 months (Fig. 1D) confirms that spine density is significantly decreased in $Z c 3 h 14^{\Delta e \times 13 / \Delta e \times 13}$ mice at 5 months $(p<.0005 ;+/+n=33$ neurons, 3 mice; $\Delta 13 / \Delta 13 n=33$ neurons, 3 mice). Together, these data demonstrate that loss of 
ZC3H14 in mice results in reduced dendritic spine density in the dentate gyrus at 5 months, with no statistically significant difference detected in this brain region at P7.

\section{Loss of ZC3H14 does not alter dendritic arbor development in cultured primary hippocampal neurons}

We previously showed that $\mathrm{ZC} 3 \mathrm{H} 14$ is found in neurites of cultured neurons (Bienkowski et al., 2017). To determine whether $\mathrm{ZC} 3 \mathrm{H} 14$ is required for normal dendritic development, we cultured primary hippocampal neurons from $Z c 3 h 14^{+/+}(+/+)$and Zc3h14 $4^{\Delta e x 13 / \Delta e x 13}(\Delta 13 / \Delta 13)$ E17.5 mouse brains as described in Materials and Methods. Neurons were transfected with GFP, to visualize neuronal morphology, and then fixed at DIV12. We did not detect any qualitative differences between the dendritic arbors of $Z c 3 h 14^{+/+}$and Zc3h14 ${ }^{\Delta e \times 13 / \Delta e x 13}$ hippocampal neurons (Fig. 2A). To analyze the morphology of these cultured neurons $(+/+n=54$ neurons, $\Delta 13 / \Delta 13 n=54$ neurons $)$, we measured both the total dendritic length (Fig. 2B) and the number of dendritic tips (Fig. 2C). To assess dendritic arbor complexity, we performed Sholl analysis (Sholl, 1953), which counts the number of dendritic branches crossing concentric circles at regular radial distances away from the soma $(+/+n=51$ neurons, $\Delta 13 / \Delta 13$ n=51 neurons) (Fig. 2D). In all these analyses, no statistically significant differences were identified between $Z c 3 h 14^{+/+}$and $Z c 3 h 14^{\Delta e \times 13 / \Delta e x 13}$ neurons ( $\left.p>0.05\right)$, suggesting that $Z C 3 H 14$ is not required for proper dendritic arbor development in vitro.

\section{Loss of ZC3H14 causes a decrease in dendritic spine density in cultured primary hippocampal neurons}

As $Z c 3 h 14^{\Delta \operatorname{ex13/\Delta ex13}}$ neurons show reduced spine density in brain tissue compared to control Zc3h14 ${ }^{+/+}$neurons (Fig. 1B,D), we employed an in vitro culture system to further analyze dendritic spine density and morphology. DIV11 primary hippocampal neurons were co-transfected with GFP and mRuby-tagged Lifeact (Lifeact-mRuby), a small actin-binding peptide that labels dendritic spines (Riedl et al., 2008), to visualize dendritic spines. Neurons were then fixed and imaged at DIV19. We first 
compared neurons from control $Z c 3 h 14^{+/+}$mice to neurons from $Z c 3 h 14^{\Delta e \times 13 / \Delta e x 13}$ mice (Fig. 3A). Semiautomated quantification reveals a statistically significant decrease $(p<0.03)$ in dendritic spine density in neurons lacking ZC3H14 (Fig. 3B).

To confirm that the decrease in spine density observed in neurons cultured from $Z c 3 h 14^{\Delta e \times 13 / \Delta e \times 13}$ mice results from the loss of $\mathrm{ZC} 3 \mathrm{H} 14$ specifically, we performed a rescue experiment. Exogenous ZC3H14 was co-transfected into DIV11 hippocampal neurons along with Lifeact-mRuby, and cells were then fixed and imaged at DIV19. For this experiment, we included two different isoforms of ZC3H14 (Fig. 3A,C) generated by alternative splicing (Leung et al., 2009). Both ZC3H14 Isoform 1 (Iso 1) and Isoform 3 (Iso 3) include the functionally important domains of ZC3H14, namely the zinc finger RNA binding domain (Fasken, Corbett, \& Stewart, 2019; S. M. Kelly et al., 2010) and the N-terminal PWI-like domain (Fasken et al., 2019; Grant et al., 2008), as well as a predicted nuclear localization signal (Fig. $3 \mathrm{C})$. These $\mathrm{ZC} 3 \mathrm{H} 14$ isoforms are primarily localized to the nucleus but can be detected in the cytoplasm of neurons (Bienkowski et al., 2017; Guthrie et al., 2011; Hector et al., 2002; Morris \& Corbett, 2018). As shown in Figure $3 A(\Delta 13 / \Delta 13+$ lso1 and $\Delta 13 / \Delta 13+$ lso3), exogenous expression of either $\mathrm{ZC} 3 \mathrm{H} 14$ Iso1 or $\mathrm{ZC} 3 \mathrm{H} 14$ Iso3 appears to rescue dendritic spine density, which is confirmed through a semi-automated quantitative analysis of dendritic spine density $[\Delta 13 / \Delta 13(+\mid$ so 1$) p<0.01$; $\Delta 13 / \Delta 13$ (+lso3) $p<0.02$ ] (Fig. 3B). These data indicate that the loss of ZC3H14 reduces dendritic spine density in mature primary hippocampal neurons in vitro.

The morphology of dendritic spines is heterogeneous, often representing differences in their stability and function (Bosch \& Hayashi, 2012; J. N. Bourne \& Harris, 2008). To determine if the loss of ZC3H14 affects spine morphology in DIV19 hippocampal neurons, we classified each spine as "Stubby", "Thin”, or "Mushroom” (Arellano, Benavides-Piccione, Defelipe, \& Yuste, 2007; J. Bourne \& Harris, 2007; Peters \& Kaiserman-Abramof, 1970; Swanger et al., 2011) according to both length and the head width to neck width ratio (Fig. 4A). For this analysis, 3D reconstructions of dendritic branches were generated, and individual spines from control Zc3h14 ${ }^{+/+}(+/+), Z c 3 h 14^{\Delta \operatorname{ex13} / \Delta e \times 13}(\Delta 13 / \Delta 13)$,

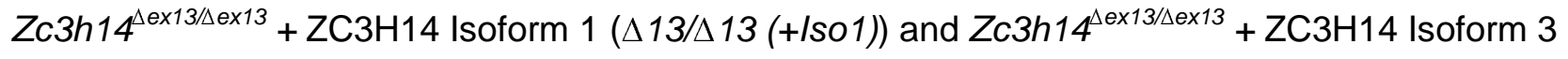


( $\Delta 13 / \Delta 13(+$ lso3)) neurons were classified as stubby- (purple), thin- (light blue), or mushroom- (dark red) type (Fig. 4B). Semi-automated quantitation revealed no statistically significant changes in the density of either stubby- or thin-type spines for any of the samples examined (Fig. 4C). In contrast, we detected a statistically significant decrease in the density of mushroom-type spines present in $\Delta 13 / \Delta 13$ neurons as compared to control $+/+$ neurons $(p=0.0002 ;+/+n=18$ neurons, $\Delta 13 / \Delta 13 n=18$ neurons). This decrease in mushroom-type spines is rescued by exogenous expression of either ZC3H14 Isoform 1 [compare $\Delta 13 / \Delta 13(+$ lso 1$)$ neurons to $\Delta 13 / \Delta 13$ neurons $(p<0.0001 ; \Delta 13 / \Delta 13(+$ lso 1$) n=23$ neurons $)$ ] or ZC3H14 Isoform 3 [compare $\Delta 13 / \Delta 13$ (+lso3) neurons to $\Delta 13 / \Delta 13$ neurons $(p<0.002 ; \Delta 13 / \Delta 13$ (+lso3) $\mathrm{n}=19$ neurons)]. Taken together, these results demonstrate that loss of ZC3H14 leads to an overall decrease in the number of mushroom-shaped spines in cultured hippocampal neurons at DIV19.

\section{Overexpression of ZC3H14 increases dendritic spine density, specifically by increasing the} number of thin spines

Loss of $\mathrm{ZC} 3 \mathrm{H} 14$ causes a decrease in dendritic spine density (Fig. 3,4). To further test a role for ZC3H14 in modulating dendritic spine morphology, we examined whether an increase in the level of ZC3H14 impacts dendritic spine density. For this analysis, primary hippocampal neurons from control Zc3h14 ${ }^{+/+}$mice were co-transfected at DIV11 with Lifeact-mRuby and GFP (+/+), GFP-ZC3H14Isoform1 $(+/+(+$ Iso1)), or GFP-ZC3H14-Isofom3 $(+/+(+/$ so3 $))$, and then fixed and imaged at DIV19

(Fig. 5A). Semi-automated quantification of spine density shows a statistically significant increase in spine density in $+/+(+/ s 01)$ neurons as compared to control $+/+[(p<0.0005 ;+/+n=21$ neurons, $+/+$ (+lso1) $n=14$ neurons)], but no significant difference in spine density in $+/+(+l$ so3) neurons as compared to control $+/+[(p>0.05 ;+/+(+/ s o 3) n=19$ neurons $)]$ (Fig. 5B). This analysis reveals that overexpression of $\mathrm{ZC} 3 \mathrm{H} 14$ Isoform 1, but not $\mathrm{ZC} 3 \mathrm{H} 14$ isoform 3, causes a statistically significant increase in dendritic spine density in vitro.

To assess whether overexpression of $\mathrm{ZC} 3 \mathrm{H} 14$ alters the density of specific dendritic spine subtypes, individual spines were 3D reconstructed to measure their morphology and classify each 
spine as stubby- (purple), thin- (light blue), or mushroom-type (dark red). Representative reconstructions for $+/+,+/+(+/ s 01)$, and +/+ (+lso3) DIV19 primary hippocampal neurons are shown in Figure 6A. Semi-automated analysis revealed a significant increase in thin-type spines in neurons overexpressing ZC3H14 Isoform 1 [(compare $+/+$ and $+/+(+/ s 01)$ neurons $(p<0.0001)]$ with no statistically significant differences in stubby- or mushroom-type (Fig 6B). There were no significant changes in any of the dendritic spine classifications in neurons overexpressing ZC3H14 Isoform 3 compared to $+/+$. The increase specifically in thin-type spines, with no difference in stubby- or mushroom-type spines, in +/+ (+lso1) DIV19 hippocampal neurons is consistent with a model where levels of $\mathrm{ZC} 3 \mathrm{H} 14$ must be tightly regulated to ensure proper dendritic spine morphology.

\section{$\mathrm{ZC} 3 \mathrm{H} 14$ is present in synaptosomes and loss of $\mathrm{ZC} 3 \mathrm{H} 14$ results in increased steady state levels of CaMKIla in synaptosomes}

Previous work has demonstrated that there is a pool of $\mathrm{ZC} 3 \mathrm{H} 14$ present in the cytoplasm of neurons (Bienkowski et al., 2017; Morris \& Corbett, 2018). To determine whether ZC3H14 is present in synaptosomes, which contain postsynaptic dendritic spines and presynaptic terminals (Chicurel, Terrian, \& Potter, 1993), fractionation was performed as illustrated in Figure 7A. We isolated three fractions from postnatal day 0 (P0) whole brains: the homogenate (Hom), cytosol (Cyt), and synaptosomes (Syn). Synaptophysin, a protein localized specifically to synaptic vesicle membranes (Wiedenmann \& Franke, 1985), is enriched in the synaptosome (Syn) fraction from this preparation (Fig. 7B), providing evidence for successful enrichment of synaptosomal proteins. Immunoblotting

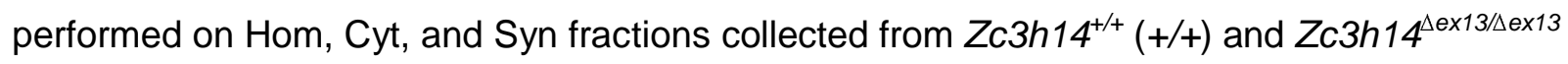
$(\Delta 13 / \Delta 13) \mathrm{PO}$ whole brains show that $\mathrm{ZC} 3 \mathrm{H} 14$ is detected in all three fractions, including synaptosomes (Fig. $7 \mathrm{C}$ ). As a control, no full length $\mathrm{ZC} 3 \mathrm{H} 14$ protein is detected in the samples from the $\Delta 13 / \Delta 13$ brains. This demonstrates that $\mathrm{ZC} 3 \mathrm{H} 14$ is present in synaptosomes.

As previous studies have implicated $\mathrm{ZC} 3 \mathrm{H} 14$ in regulating the expression of CaMKII (Bienkowski et al., 2017; Rha et al., 2017), immunoblotting was performed to assess levels of CaMKII and PSD-95, 
a protein critical for maintaining the post synaptic density in dendritic spines (Hunt, Schenker, \& Kennedy, 1996), specifically in synaptosomes (Fig. 7D). Results of this analysis show an increase in the level of CaMKIla detected in the $\Delta 13 / \Delta 13$ synaptosomes compared to control, which is statistically significant $(p<0.04 ;+/+n=3, \Delta 13 / \Delta 13 n=3)$ (Fig. 7E). In contrast, no statistically significant difference $(p>0.05)$ was detected in the level of PSD-95 present in these synaptosomal fractions (Fig. 7D,E). Taken together, these data support a model where $\mathrm{ZC} 3 \mathrm{H} 14$ is required for proper steady-state levels of CaMKIla protein in synaptosomes.

\section{Discussion}

This study employs a previously generated mouse model, Zc3h14 $4^{\operatorname{sex} 13 / \Delta e \times 13}$ (Rha et al., 2017), to explore the requirement for $\mathrm{ZC} 3 \mathrm{H} 14$ in dendritic spine density and morphology. Results of this analysis demonstrate that $\mathrm{ZC} 3 \mathrm{H} 14$ is essential for proper dendritic spine density based on both in situ analysis of mouse brain and studies of cultured primary hippocampal neurons. In both cases, loss of ZC3H14 causes a decrease in overall dendritic spine density. Studies in the cultured primary hippocampal neurons reveal that this decrease in spine density is primarily due to loss of mushroom-type spines. Overexpression of $\mathrm{ZC} 3 \mathrm{H} 14$ in cultured hippocampal neurons increases overall dendritic spine density, primarily driven by an increase in the number of thin-type spines. As $\mathrm{ZC} 3 \mathrm{H} 14$ is present in synaptosomes, these changes in dendritic spine morphology could result from altered local translation. Finally, loss of $\mathrm{ZC} 3 \mathrm{H} 14$ causes an increase in levels of CaMKIla in synaptosomes, which could be linked to changes in dendritic spine morphology.

Either loss of $\mathrm{ZC} 3 \mathrm{H} 14$ or an increase in levels achieved through transfection of cultured primary hippocampal neurons alters overall dendritic spine density. While the loss of $\mathrm{ZC} 3 \mathrm{H} 14$ causes a decrease in dendritic spine density, overexpression of $\mathrm{ZC} 3 \mathrm{H} 14$, causes an increase. The subtypes of dendritic spines affected in these two cases are distinct from one another. Loss of ZC3H14 affects mushroom-type spines, while overexpression of $\mathrm{ZC} 3 \mathrm{H} 14$ increases the number of thin-type spines. The decrease in mushroom-type spines observed in neurons cultured from Zc3h14 ${ }^{\Delta e \times 13 / \Delta e \times 13}$ mouse 
hippocampi compared to control (Fig. 4) is rescued by restoring levels of ZC3H14 via transfection, providing evidence that the changes are due to loss of $\mathrm{ZC} 3 \mathrm{H} 14$. The overexpression studies are more challenging to interpret because levels of overexpression of $\mathrm{ZC} 3 \mathrm{H} 14$ likely vary among the neurons transfected. The neuronal cultures were co-stained to detect $\mathrm{ZC} 3 \mathrm{H} 14$, but endogenous $\mathrm{ZC} 3 \mathrm{H} 14$ is already abundant in nuclear speckles (Guthrie et al., 2011; Leung et al., 2009), making identification of neurons with overexpression of ZC3H14 difficult to identify. However, transfection of ZC3H14 into +/+ neurons did cause a statistically significant increase specifically in thin-type spines, providing some evidence that $\mathrm{ZC} 3 \mathrm{H} 14$ can regulate different types of spines. Future studies could employ variants of ZC3H14 with decreased RNA binding, which would first need to be generated and characterized, to assess whether this function is required both for the rescue and the effects observed upon overexpression of $\mathrm{ZC} 3 \mathrm{H} 14$.

Dendritic spines are highly heterogeneous in both function and morphology (Alvarez \& Sabatini, 2007). Here, we detected different effects with regard to stubby, thin, and mushroom-type spines in response to loss or gain of $\mathrm{ZC} 3 \mathrm{H} 14$. Stubby spines are characterized by their lack of a definable head or neck, as well as their short squat appearance. While they contain large excitatory synapses, stubby spines are considered to be immature, and hence are not found as readily in adult brains (Harris, Jensen, \& Tsao, 1992). Thin spines are fairly dynamic with long thin necks and small bulbous heads, which contain small excitatory synapses. Mushroom spines are more static with thin necks and broad heads that contain the largest excitatory synapses. Previous studies have linked spine head volume with the size of the postsynaptic density (PSD), a dense and dynamic meshwork of proteins that mediate postsynaptic signaling (Arellano et al., 2007; Harris et al., 1992). Moreover, spine head volume correlates with AMPA receptor density and NMDA receptor-dependent calcium signaling, thus connecting spine morphology with synaptic strength (Majewska, Tashiro, \& Yuste, 2000; Matsuzaki et al., 2001; Noguchi et al., 2005). Loss of ZC3H14 leads to a reduction in dendritic spine density, both in situ and in vitro. This reduction in vitro is the result of a decrease specifically in the number of mushroom-shaped spines. Importantly, we were able to rescue both the overall and mushroom-specific 
reductions in spine density, by exogenously expressing $\mathrm{ZC} 3 \mathrm{H} 14$ in individual hippocampal neurons from $Z c 3 h 14^{\Delta e \times 13 / \Delta e x 13}$ mice. Together, this suggests that $\mathrm{ZC} 3 \mathrm{H} 14$ could be required for the development of mature mushroom-shaped spines. Alternatively or in addition, ZC3H14 could play a role in the maintenance or stability of mushroom spines. Future experiments capable of monitoring spine dynamics would be required to distinguish between these possible roles for $\mathrm{ZC} 3 \mathrm{H} 14$ in modulating mushroom-type spines.

Our in situ studies examined the dentate gyrus. The dentate gyrus is a region of the hippocampus highly associated with learning and memory, particularly spatially-based tasks (Barak et al., 2013; O'Malley, O'Connell, Murphy, \& Regan, 2000; Xavier \& Costa, 2009). Likely due to the tight level of control required at excitatory synapses for proper neuronal function, a number of neurological disorders show alterations in spine density in various regions of the brain, including the dentate gyrus (Grossman et al., 2010; Penzes, Cahill, Jones, VanLeeuwen, \& Woolfrey, 2011; Phillips \& Pozzo-Miller, 2015; Scheff, Sparks, \& Price, 1996). Of particular note, altered spine density in the dentate gyrus has been observed in a knockout mouse model of Fragile X Syndrome (Grossman et al., 2010), the most common form of inherited intellectual disability (Hagerman et al., 2017). The Fragile X Mental Retardation (FMRP) RNA binding protein, which is lost in Fragile X Syndrome, is implicated in proper regulation of local translation in neurons (Feng et al., 1997; Zalfa, Achsel, \& Bagni, 2006), providing an example of a ubiquitously expressed RNA-binding proteins required to regulate dendritic spine properties (Ifrim, Williams, \& Bassell, 2015). Our studies show a significant decrease in spine density in the dentate granule neurons of adult $Z c 3 h 14^{\Delta e x 13 / \Delta e x 13}$ mice in situ, which is consistent with prior studies of these mice where a defect in working memory was detected in adult Zc3h14 ${ }^{\Delta e \times 13 / \Delta e \times 13}$ mice in a spatially-based learning/memory behavioral assay (Rha et al., 2017). These results suggest that the ZC3H14 RNA binding protein could play a similar role to FMRP in regulating transcripts critical for proper dendritic spine function. Consistent with this idea, studies in Drosophila identified functional and physical interactions between fly FMRP and the ZC3H14 orthologue Nab2 (Bienkowski et al., 2017). 
detected at five months, but not at postnatal day 7 (P7). Regulation of dendritic spines in the brain is a highly spatiotemporally dynamic process and is dependent on both the stage of brain development and the brain region (C. C. Chen, Lu, \& Zuo, 2014; Stein \& Zito, 2019). This age-specific phenotype could suggest a role for $\mathrm{ZC} 3 \mathrm{H} 14$ in dendritic spine maintenance, which is an age-dependent stage of neuronal development that initiates in mice during early adulthood. By contrast, mice at P7 are in the spinogenesis phase of neuronal development. Often neurological disorders show altered dendritic spine density at specific stages of neuronal development rather than as a constant phenotype across developmental stages (Forrest et al., 2018; Phillips \& Pozzo-Miller, 2015). Performing Golgi staining of $Z c 3 h 14^{\Delta e \times 13 / \Delta e \times 13}$ mouse brain tissue during the spine pruning stage of neuronal development, which occurs between the spinogenesis and spine maintenance phases, could help to more precisely define the role of $\mathrm{ZC} 3 \mathrm{H} 14$. These investigations could be important to understand how loss of $\mathrm{ZC} 3 \mathrm{H} 14$ in humans leads to intellectual disability.

The finding that loss of $\mathrm{ZC} 3 \mathrm{H} 14$ leads to a reduction in mushroom-shaped spines raises the question of what consequences this change could have for neuronal function in $Z c 3 h 14^{\Delta e \times 13 / \Delta e \times 13}$ mice. First, it is important to note that individual spines undergo changes in shape during development and in response to stimuli (Berry \& Nedivi, 2017; Hotulainen \& Hoogenraad, 2010). The turnover of dendritic spines, as well as changes in their growth and retraction, is tied to alterations in brain circuitry that underlie learning and memory (Forrest et al., 2018; Yuste, 2011). For example, early longitudinal studies of the mouse barrel cortex demonstrated how spine and synapse formation/stabilization, as well as destabilization, occur in response to novel sensory experiences (Holtmaat, Wilbrecht, Knott, Welker, \& Svoboda, 2006; Zuo, Yang, Kwon, \& Gan, 2005). Similarly, the size of individual spines and synapses from cultured neurons in vitro, can be increased or decreased in response to specific patterns of activity (Bosch \& Hayashi, 2012; Ho, Lee, \& Martin, 2011). For this reason, thin spines, which are more dynamic and structurally flexible, are thought to represent "learning spines" (J. Bourne \& Harris, 2007). Conversely, stable mature mushroom-shaped spines likely represent "memory spines" (Borczyk et al., 2019; J. Bourne \& Harris, 2007). Thus, our data showing that Zc3h14 ${ }^{\Delta e \times 13 / \Delta e \times 13}$ mice have a 
reduction in mushroom-shaped spines are consistent with earlier findings that $Z c 3 h 14^{\Delta e \times 13 / \Delta e \times 13}$ mice exhibit defects in working memory, but display intact learning (Bienkowski et al., 2017). These findings are also remarkably consistent with results from Drosophila where pan-neuronal depletion of the fly ZC3H14 orthologue, Nab2, caused short-term memory defects while learning remained intact (S. M. Kelly et al., 2016). Thus, changes in the dendritic spine morphology upon loss of ZC3H14 are consistent with behavioral consequences that have been documented in multiple model organisms lacking $\mathrm{ZC} 3 \mathrm{H} 14$.

Zc3h14 ${ }^{\Delta e x 13 / \Delta e x 13}$ mice display an approximately $140 \%$ increase in CaMKIla levels in

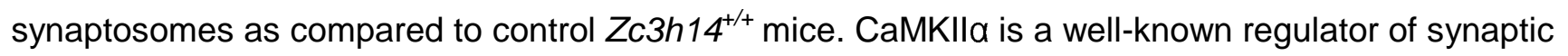
plasticity and dendritic spine morphology (Coultrap \& Bayer, 2012; Coultrap et al., 2014; Herring \& Nicoll, 2016; Kim \& Hayashi, 2014). Thus, regulation of CaMKIla levels could provide a possible mechanism by which the loss of $\mathrm{ZC} 3 \mathrm{H} 14$ induces changes in spine density and morphology. Interestingly, we also identified $\mathrm{ZC} 3 \mathrm{H} 14$ itself as a component of synaptosomes. This raises the intriguing possibility that $\mathrm{ZC} 3 \mathrm{H} 14$ could regulate the local translation of target transcripts, including the CaMKIla RNA. In a previous study characterizing the Zc3h14 $4^{\Delta e \times 13 / \Delta e \times 13}$ mice, we provided evidence that ZC3H14 may regulate CaMKIla expression (Rha et al., 2017). Specifically, ZC3H14 binds to the CaMKIla transcript and loss of ZC3H14 increases steady state levels of CaMKIla in the brain (Rha et al., 2017). These findings are bolstered by a study in Drosophila in which Nab2 not only interacts with the CaMKII transcript but also represses a CaMKII translational reporter in neurons (Bienkowski et al., 2017). Previous studies have shown that CaMKIla mRNA is localized to dendrites, and that CaMKIla expression in dendrites is dynamically regulated by local translation (Burgin et al., 1990; Mayford, Baranes, Podsypanina, \& Kandel, 1996; Paradies \& Steward, 1997; Scheetz, Nairn, \& ConstantinePaton, 2000). Consequently, inhibiting CaMKIla synthesis specifically in dendrites, but not in the soma, negatively affects synaptic plasticity and long-term memory but not learning (Aakalu, Smith, Nguyen, Jiang, \& Schuman, 2001; Ashraf, McLoon, Sclarsic, \& Kunes, 2006; Miller et al., 2002; Neant-Fery et al., 2012). Our current results providing evidence that $\mathrm{ZC} 3 \mathrm{H} 14$ is present in synaptosomes raises the 
possibility that $\mathrm{ZC} 3 \mathrm{H} 14$ directly regulates the levels of CaMKIla, potentially via modulating local translation. Further studies will be required to test this model.

Taken together, the results presented here provide the first evidence that $\mathrm{ZC} 3 \mathrm{H} 14$ is important for proper dendritic spine density and specifically for dendrites to maintain normal numbers of mushroomtype spines. These findings are consistent with behavioral results showing that mice lacking $\mathrm{ZC} 3 \mathrm{H} 14$ show defects in spatially-based memory tasks (Rha et al., 2017). Growing evidence places the RNA binding protein $\mathrm{ZC} 3 \mathrm{H} 14$ in a group with other RNA binding proteins such as FMRP and others that are implicated in regulating local translation at the synapse (Maximilian Paul Thelen \& Kye, 2020). While further work is required to define the molecular mechanism by which $\mathrm{ZC} 3 \mathrm{H} 14$ contributes to proper dendritic spine morphology, this work adds to our understanding of how loss of $\mathrm{ZC} 3 \mathrm{H} 14$ could contribute to neuronal dysfunction.

Data Availability Statement: The data that support the findings of this study are openly available for sharing. There are no data deposited into any repository. 


\section{References}

Aakalu, G., Smith, W. B., Nguyen, N., Jiang, C., \& Schuman, E. M. (2001). Dynamic visualization of local protein synthesis in hippocampal neurons. Neuron, 30(2), 489-502.

Adrian, M., Kusters, R., Wierenga, C. J., Storm, C., Hoogenraad, C. C., \& Kapitein, L. C. (2014). Barriers in the brain: resolving dendritic spine morphology and compartmentalization. Front Neuroanat, 8, 142. doi: 10.3389/fnana.2014.00142

Al-Nabhani, M., Al-Rashdi, S., Al-Murshedi, F., Al-Kindi, A., Al-Thihli, K., Al-Saegh, A., ... Al-Maawali, A. (2018). Reanalysis of exome sequencing data of intellectual disability samples: Yields and benefits. Clinical Genetics, 94(6), 495-501. doi: 10.1111/cge.13438

Alvarez, V. A., \& Sabatini, B. L. (2007). Anatomical and Physiological Plasticity of Dendritic Spines. Annu Rev Neurosci, 30(1), 79-97. doi: 10.1146/annurev.neuro.30.051606.094222

Anderson, J. T., Wilson, S. M., Datar, K. V., \& Swanson, M. S. (1993). NAB2: a yeast nuclear polyadenylated RNA-binding protein essential for cell viability. Mol Cell Biol, 13(5), 2730-2741.

Arellano, J. I., Benavides-Piccione, R., Defelipe, J., \& Yuste, R. (2007). Ultrastructure of dendritic spines: correlation between synaptic and spine morphologies. Front Neurosci, 1(1), 131-143. doi: 10.3389/neuro.01.1.1.010.2007

Ashraf, S. I., McLoon, A. L., Sclarsic, S. M., \& Kunes, S. (2006). Synaptic protein synthesis associated with memory is regulated by the RISC pathway in Drosophila. Cell, 124(1), 191-205. doi: 10.1016/j.cell.2005.12.017

Barak, B., Okun, E., Ben-Simon, Y., Lavi, A., Shapira, R., Madar, R., . . Ashery, U. (2013). Neuronspecific expression of tomosyn1 in the mouse hippocampal dentate gyrus impairs spatial learning and memory. Neuromolecular Med, 15(2), 351-363. doi: 10.1007/s12017-013-8223-4

Berry, K. P., \& Nedivi, E. (2017). Spine Dynamics: Are They All the Same? Neuron, 96(1), 43-55. doi: 10.1016/j.neuron.2017.08.008

Besse, F., \& Ephrussi, A. (2008). Translational control of localized mRNAs: restricting protein synthesis in space and time. Nat Rev Mol Cell Biol, 9(12), 971-980. doi: 10.1038/nrm2548

Bienkowski, R. S., Banerjee, A., Rounds, J. C., Rha, J., Omotade, O. F., Gross, C., . . Moberg, K. H. (2017). The Conserved, Disease-Associated RNA Binding Protein dNab2 Interacts with the Fragile X Protein Ortholog in Drosophila Neurons. Cell Rep, 20(6), 1372-1384. doi: 10.1016/j.celrep.2017.07.038

Borczyk, M., Sliwinska, M. A., Caly, A., Bernas, T., \& Radwanska, K. (2019). Neuronal plasticity affects correlation between the size of dendritic spine and its postsynaptic density. Sci Rep, 9(1), 1693. doi: $10.1038 / \mathrm{s} 41598-018-38412-7$

Bosch, M., \& Hayashi, Y. (2012). Structural plasticity of dendritic spines. Curr Opin Neurobiol, 22(3), 383-388. doi: 10.1016/j.conb.2011.09.002

Bourne, J., \& Harris, K. M. (2007). Do thin spines learn to be mushroom spines that remember? Curr Opin Neurobiol, 17(3), 381-386. doi: 10.1016/j.conb.2007.04.009

Bourne, J. N., \& Harris, K. M. (2008). Balancing structure and function at hippocampal dendritic spines. Annu Rev Neurosci, 31, 47-67. doi: 10.1146/annurev.neuro.31.060407.125646

Burgin, K. E., Waxham, M. N., Rickling, S., Westgate, S. A., Mobley, W. C., \& Kelly, P. T. (1990). In situ hybridization histochemistry of $\mathrm{Ca2}+$ /calmodulin-dependent protein kinase in developing rat brain. J Neurosci, 10(6), 1788-1798.

Cajigas, I. J., Tushev, G., Will, T. J., tom Dieck, S., Fuerst, N., \& Schuman, E. M. (2012). The local transcriptome in the synaptic neuropil revealed by deep sequencing and high-resolution imaging. Neuron, 74(3), 453-466. doi: 10.1016/j.neuron.2012.02.036

Chen, C. C., Lu, J., \& Zuo, Y. (2014). Spatiotemporal dynamics of dendritic spines in the living brain. Front Neuroanat, 8, 28. doi: 10.3389/fnana.2014.00028

Chen, Y., \& Sabatini, B. L. (2012). Signaling in dendritic spines and spine microdomains. Curr Opin Neurobiol, 22(3), 389-396. doi: 10.1016/j.conb.2012.03.003 
Chicurel, M. E., Terrian, D. M., \& Potter, H. (1993). mRNA at the synapse: analysis of a synaptosomal preparation enriched in hippocampal dendritic spines. J Neurosci, 13(9), 4054-4063. doi: 10.1523/JNEUROSCI.13-09-04054.1993

Cooper, T. A., Wan, L., \& Dreyfuss, G. (2009). RNA and disease. Cell, 136(4), 777-793. doi: 10.1016/j.cell.2009.02.011

Coultrap, S. J., \& Bayer, K. U. (2012). CaMKII regulation in information processing and storage. Trends Neurosci, 35(10), 607-618. doi: 10.1016/j.tins.2012.05.003

Coultrap, S. J., Freund, R. K., O'Leary, H., Sanderson, J. L., Roche, K. W., Dell'Acqua, M. L., \& Bayer, K. U. (2014). Autonomous CaMKII mediates both LTP and LTD using a mechanism for differential substrate site selection. Cell Rep, 6(3), 431-437. doi: 10.1016/j.celrep.2014.01.005

De Roo, M., Klauser, P., Garcia, P. M., Poglia, L., \& Muller, D. (2008). Spine dynamics and synapse remodeling during LTP and memory processes. Prog Brain Res, 169, 199-207. doi: 10.1016/s0079-6123(07)00011-8

Du, F. (2019). Golgi-Cox Staining of Neuronal Dendrites and Dendritic Spines With FD Rapid GolgiStain Kit. Curr Protoc Neurosci, 88(1), e69. doi: 10.1002/cpns.69

Fasken, M. B., Corbett, A. H., \& Stewart, M. (2019). Structure-function relationships in the Nab2 polyadenosine-RNA binding Zn finger protein family. Protein Sci, 28(3), 513-523. doi: 10.1002/pro.3565

Feng, Y., Gutekunst, C. A., Eberhart, D. E., Yi, H., Warren, S. T., \& Hersch, S. M. (1997). Fragile X mental retardation protein: nucleocytoplasmic shuttling and association with somatodendritic ribosomes. J Neurosci, 17(5), 1539-1547.

Fiala, J. C., Spacek, J., \& Harris, K. M. (2002). Dendritic spine pathology: cause or consequence of neurological disorders? Brain Res Brain Res Rev, 39(1), 29-54.

Forrest, M. P., Parnell, E., \& Penzes, P. (2018). Dendritic structural plasticity and neuropsychiatric disease. Nat Rev Neurosci, 19(4), 215-234. doi: 10.1038/nrn.2018.16

Fukunaga, K., Shioda, N., \& Miyamoto, E. (2009). The Function of CaM Kinase II in Synaptic Plasticity and Spine Formation. In A. Lajtha \& K. Mikoshiba (Eds.), Handbook of Neurochemistry and Molecular Neurobiology: Neural Signaling Mechanisms (pp. 163-183). Boston, MA: Springer US.

Garcia-Lopez, P., Garcia-Marin, V., \& Freire, M. (2007). The discovery of dendritic spines by Cajal in 1888 and its relevance in the present neuroscience. Prog Neurobiol, 83(2), 110-130. doi: 10.1016/j.pneurobio.2007.06.002

Glock, C., Heumuller, M., \& Schuman, E. M. (2017). mRNA transport \& local translation in neurons. Curr Opin Neurobiol, 45, 169-177. doi: 10.1016/j.conb.2017.05.005

Grant, R. P., Marshall, N. J., Yang, J. C., Fasken, M. B., Kelly, S. M., Harreman, M. T., . . Stewart, M. (2008). Structure of the N-terminal Mlp1-binding domain of the Saccharomyces cerevisiae mRNA-binding protein, Nab2. J Mol Biol, 376(4), 1048-1059. doi: 10.1016/j.jmb.2007.11.087

Green, D. M., Marfatia, K. A., Crafton, E. B., Zhang, X., Cheng, X., \& Corbett, A. H. (2002). Nab2p is required for poly $(A)$ RNA export in Saccharomyces cerevisiae and is regulated by arginine methylation via Hmt1p. J Biol Chem, 277(10), 7752-7760. doi: 10.1074/jbc.M110053200

Grossman, A. W., Aldridge, G. M., Lee, K. J., Zeman, M. K., Jun, C. S., Azam, H. S., . . Rhyu, I. J. (2010). Developmental characteristics of dendritic spines in the dentate gyrus of Fmr1 knockout mice. Brain Res, 1355, 221-227. doi: 10.1016/j.brainres.2010.07.090

Guthrie, C. R., Greenup, L., Leverenz, J. B., \& Kraemer, B. C. (2011). MSUT2 is a determinant of susceptibility to tau neurotoxicity. Hum Mol Genet, 20(10), 1989-1999. doi: 10.1093/hmg/ddr079

Hagerman, R. J., Berry-Kravis, E., Hazlett, H. C., Bailey, D. B., Moine, H., Kooy, R. F., . . Hagerman, P. J. (2017). Fragile X syndrome. Nature Reviews Disease Primers, 3(1), 17065. doi: 10.1038/nrdp.2017.65

Harris, K. M., Jensen, F. E., \& Tsao, B. (1992). Three-dimensional structure of dendritic spines and synapses in rat hippocampus (CA1) at postnatal day 15 and adult ages: implications for the maturation of synaptic physiology and long-term potentiation. J Neurosci, 12(7), 2685-2705. doi: 10.1523/jneurosci.12-07-02685.1992 
Hector, R. E., Nykamp, K. R., Dheur, S., Anderson, J. T., Non, P. J., Urbinati, C. R., . . Swanson, M. S. (2002). Dual requirement for yeast hnRNP Nab2p in mRNA poly(A) tail length control and nuclear export. Embo j, 21(7), 1800-1810. doi: 10.1093/emboj/21.7.1800

Herring, B. E., \& Nicoll, R. A. (2016). Long-Term Potentiation: From CaMKII to AMPA Receptor Trafficking. Annu Rev Physiol, 78, 351-365. doi: 10.1146/annurev-physiol-021014-071753

Ho, V. M., Lee, J. A., \& Martin, K. C. (2011). The cell biology of synaptic plasticity. Science, 334(6056), 623-628. doi: 10.1126/science.1209236

Holt, C. E., \& Schuman, E. M. (2013). The central dogma decentralized: new perspectives on RNA function and local translation in neurons. Neuron, 80(3), 648-657. doi: 10.1016/j.neuron.2013.10.036

Holtmaat, A., Wilbrecht, L., Knott, G. W., Welker, E., \& Svoboda, K. (2006). Experience-dependent and cell-type-specific spine growth in the neocortex. Nature, 441(7096), 979-983. doi: 10.1038 /nature 04783

Hotulainen, P., \& Hoogenraad, C. C. (2010). Actin in dendritic spines: connecting dynamics to function. J Cell Biol, 189(4), 619-629. doi: 10.1083/jcb.201003008

Huber, K. M., Kayser, M. S., \& Bear, M. F. (2000). Role for rapid dendritic protein synthesis in hippocampal mGluR-dependent long-term depression. Science, 288(5469), 1254-1257.

Hunt, C. A., Schenker, L. J., \& Kennedy, M. B. (1996). PSD-95 is associated with the postsynaptic density and not with the presynaptic membrane at forebrain synapses. J Neurosci, 16(4), 13801388. doi: 10.1523/JNEUROSCI.16-04-01380.1996

Ifrim, M. F., Williams, K. R., \& Bassell, G. J. (2015). Single-Molecule Imaging of PSD-95 mRNA Translation in Dendrites and Its Dysregulation in a Mouse Model of Fragile X Syndrome. $J$ Neurosci, 35(18), 7116-7130. doi: 10.1523/JNEUROSCI.2802-14.2015

Kang, H., \& Schuman, E. M. (1996). A requirement for local protein synthesis in neurotrophin-induced hippocampal synaptic plasticity. Science, 273(5280), 1402-1406.

Kapur, M., \& Ackerman, S. L. (2018). mRNA Translation Gone Awry: Translation Fidelity and Neurological Disease. Trends Genet, 34(3), 218-231. doi: 10.1016/j.tig.2017.12.007

Kelly, S., Pak, C., Garshasbi, M., Kuss, A., Corbett, A. H., \& Moberg, K. (2012). New kid on the ID block: neural functions of the Nab2/ZC3H14 class of $\mathrm{Cys}_{3} \mathrm{His}$ tandem zinc-finger polyadenosine RNA binding proteins. RNA Biol, 9(5), 555-562. doi: 10.4161/rna.20187

Kelly, S. M., Bienkowski, R., Banerjee, A., Melicharek, D. J., Brewer, Z. A., Marenda, D. R., . . . Moberg, K. H. (2016). The Drosophila ortholog of the Zc3h14 RNA binding protein acts within neurons to pattern axon projection in the developing brain. Dev Neurobiol, 76(1), 93-106. doi: 10.1002/dneu.22301

Kelly, S. M., Leung, S. W., Apponi, L. H., Bramley, A. M., Tran, E. J., Chekanova, J. A., . . Corbett, A. H. (2010). Recognition of polyadenosine RNA by the zinc finger domain of nuclear poly(A) RNAbinding protein 2 (Nab2) is required for correct mRNA 3'-end formation. J Biol Chem, 285(34), 26022-26032. doi: 10.1074/jbc.M110.141127

Kelly, S. M., Leung, S. W., Pak, C., Banerjee, A., Moberg, K. H., \& Corbett, A. H. (2014). A conserved role for the zinc finger polyadenosine RNA binding protein, $\mathrm{ZC} 3 \mathrm{H} 14$, in control of poly $(\mathrm{A})$ tail length. Rna, 20(5), 681-688. doi: 10.1261/rna.043984.113

Kim, K., \& Hayashi, Y. (2014). CaMKII: the Swiss army knife of synaptic plasticity. J Physiol, 592(22), 4807-4808. doi: 10.1113/jphysiol.2014.284414

Lakso, M., Pichel, J. G., Gorman, J. R., Sauer, B., Okamoto, Y., Lee, E., . . Westphal, H. (1996). Efficient in vivo manipulation of mouse genomic sequences at the zygote stage. Proc Natl Acad Sci U S A, 93(12), 5860-5865. doi: 10.1073/pnas.93.12.5860

Leung, S. W., Apponi, L. H., Cornejo, O. E., Kitchen, C. M., Valentini, S. R., Pavlath, G. K., ... Corbett, A. H. (2009). Splice variants of the human ZC3H14 gene generate multiple isoforms of a zinc finger polyadenosine RNA binding protein. Gene, 439(1-2), 71-78. doi: 10.1016/j.gene.2009.02.022 
Liu-Yesucevitz, L., Bassell, G. J., Gitler, A. D., Hart, A. C., Klann, E., Richter, J. D., . . Wolozin, B. (2011). Local RNA translation at the synapse and in disease. J Neurosci, 31(45), 16086-16093. doi: 10.1523/jneurosci.4105-11.2011

Longair, M. H., Baker, D. A., \& Armstrong, J. D. (2011). Simple Neurite Tracer: open source software for reconstruction, visualization and analysis of neuronal processes. Bioinformatics, 27(17), 2453-2454. doi: 10.1093/bioinformatics/btr390

Majewska, A., Tashiro, A., \& Yuste, R. (2000). Regulation of spine calcium dynamics by rapid spine motility. J Neurosci, 20(22), 8262-8268. doi: 10.1523/jneurosci.20-22-08262.2000

Marfatia, K. A., Crafton, E. B., Green, D. M., \& Corbett, A. H. (2003). Domain analysis of the Saccharomyces cerevisiae heterogeneous nuclear ribonucleoprotein, Nab2p. Dissecting the requirements for Nab2p-facilitated poly(A) RNA export. J Biol Chem, 278(9), 6731-6740. doi: 10.1074/jbc.M207571200

Matsuzaki, M., Ellis-Davies, G. C., Nemoto, T., Miyashita, Y., lino, M., \& Kasai, H. (2001). Dendritic spine geometry is critical for AMPA receptor expression in hippocampal CA1 pyramidal neurons. Nat Neurosci, 4(11), 1086-1092. doi: 10.1038/nn736

Mayford, M., Baranes, D., Podsypanina, K., \& Kandel, E. R. (1996). The 3'-untranslated region of CaMKII alpha is a cis-acting signal for the localization and translation of mRNA in dendrites. Proc Natl Acad Sci U S A, 93(23), 13250-13255. doi: 10.1073/pnas.93.23.13250

Miller, S., Yasuda, M., Coats, J. K., Jones, Y., Martone, M. E., \& Mayford, M. (2002). Disruption of dendritic translation of CaMKIlalpha impairs stabilization of synaptic plasticity and memory consolidation. Neuron, 36(3), 507-519.

Morris, K. J., \& Corbett, A. H. (2018). The polyadenosine RNA-binding protein ZC3H14 interacts with the THO complex and coordinately regulates the processing of neuronal transcripts. Nucleic Acids Res, 46(13), 6561-6575. doi: 10.1093/nar/gky446

Neant-Fery, M., Peres, E., Nasrallah, C., Kessner, M., Gribaudo, S., Greer, C., . . Caille, I. (2012). A role for dendritic translation of CaMKIlalpha mRNA in olfactory plasticity. PLoS One, 7(6), e40133. doi: 10.1371/journal.pone.0040133

Newey, S. E., Velamoor, V., Govek, E. E., \& Van Aelst, L. (2005). Rho GTPases, dendritic structure, and mental retardation. J Neurobiol, 64(1), 58-74. doi: 10.1002/neu.20153

Noguchi, J., Matsuzaki, M., Ellis-Davies, G. C., \& Kasai, H. (2005). Spine-neck geometry determines NMDA receptor-dependent Ca2+ signaling in dendrites. Neuron, 46(4), 609-622. doi: 10.1016/j.neuron.2005.03.015

Nusser, Z., Lujan, R., Laube, G., Roberts, J. D., Molnar, E., \& Somogyi, P. (1998). Cell type and pathway dependence of synaptic AMPA receptor number and variability in the hippocampus. Neuron, 21(3), 545-559. doi: 10.1016/s0896-6273(00)80565-6

O'Malley, A., O'Connell, C., Murphy, K. J., \& Regan, C. M. (2000). Transient spine density increases in the mid-molecular layer of hippocampal dentate gyrus accompany consolidation of a spatial learning task in the rodent. Neuroscience, 99(2), 229-232. doi: 10.1016/s0306-4522(00)00182-2

Pak, C., Garshasbi, M., Kahrizi, K., Gross, C., Apponi, L. H., Noto, J. J., . . Kuss, A. W. (2011). Mutation of the conserved polyadenosine RNA binding protein, ZC3H14/dNab2, impairs neural function in Drosophila and humans. Proc Natl Acad Sci U S A, 108(30), 12390-12395. doi: 10.1073/pnas.1107103108

Paradies, M. A., \& Steward, O. (1997). Multiple subcellular mRNA distribution patterns in neurons: a nonisotopic in situ hybridization analysis. J Neurobiol, 33(4), 473-493. doi: 10.1002/(sici)10974695(199710)33:4<473::aid-neu10>3.0.co;2-d

Penzes, P., Cahill, M. E., Jones, K. A., VanLeeuwen, J. E., \& Woolfrey, K. M. (2011). Dendritic spine pathology in neuropsychiatric disorders. Nat Neurosci, 14(3), 285-293. doi: 10.1038/nn.2741

Peters, A., \& Kaiserman-Abramof, I. R. (1970). The small pyramidal neuron of the rat cerebral cortex. The perikaryon, dendrites and spines. Am J Anat, 127(4), 321-355. doi: 10.1002/aja.1001270402

Phillips, M., \& Pozzo-Miller, L. (2015). Dendritic spine dysgenesis in autism related disorders. Neurosci Lett, 601, 30-40. doi: 10.1016/j.neulet.2015.01.011 
Poon, M. M., Choi, S. H., Jamieson, C. A., Geschwind, D. H., \& Martin, K. C. (2006). Identification of process-localized mRNAs from cultured rodent hippocampal neurons. J Neurosci, 26(51), 13390-13399. doi: 10.1523/jneurosci.3432-06.2006

Ramón-Moliner, E. (1970). The Golgi-Cox technique. In W. J. H. Nauta \& S. O. E. Ebbesson (Eds.), Contemporary Methods in Neuroanatomy (pp. 32-55). New York: Springer.

Rha, J., Jones, S. K., Fidler, J., Banerjee, A., Leung, S. W., Morris, K. J., . . Corbett, A. H. (2017). The RNA-binding protein, $\mathrm{ZC} 3 \mathrm{H} 14$, is required for proper poly $(\mathrm{A})$ tail length control, expression of synaptic proteins, and brain function in mice. Hum Mol Genet, 26(19), 3663-3681. doi: 10.1093/hmg/ddx248

Riedl, J., Crevenna, A. H., Kessenbrock, K., Yu, J. H., Neukirchen, D., Bista, M., . . Wedlich-Soldner, R. (2008). Lifeact: a versatile marker to visualize F-actin. Nature Methods, 5(7), 605-607. doi: $10.1038 /$ nmeth. 1220

Scheetz, A. J., Nairn, A. C., \& Constantine-Paton, M. (2000). NMDA receptor-mediated control of protein synthesis at developing synapses. Nat Neurosci, 3(3), 211-216. doi: 10.1038/72915

Scheff, S. W., Sparks, D. L., \& Price, D. A. (1996). Quantitative assessment of synaptic density in the outer molecular layer of the hippocampal dentate gyrus in Alzheimer's disease. Dementia, 7(4), 226-232. doi: 10.1159/000106884

Scheper, G. C., van der Knaap, M. S., \& Proud, C. G. (2007). Translation matters: protein synthesis defects in inherited disease. Nat Rev Genet, 8(9), 711-723. doi: 10.1038/nrg2142

Scherrer, K. (2018). Primary transcripts: From the discovery of RNA processing to current concepts of gene expression - Review. Experimental Cell Research, 373(1), 1-33. doi: https://doi.org/10.1016/j.yexcr.2018.09.011

Schmid, M., Olszewski, P., Pelechano, V., Gupta, I., Steinmetz, L. M., \& Jensen, T. H. (2015). The Nuclear PolyA-Binding Protein Nab2p Is Essential for mRNA Production. Cell Rep, 12(1), 128139. doi: 10.1016/j.celrep.2015.06.008

Segal, M. (2005). Dendritic spines and long-term plasticity. Nat Rev Neurosci, 6(4), 277-284. doi: $10.1038 / \mathrm{nrn} 1649$

Sheng, M., \& Hoogenraad, C. C. (2007). The postsynaptic architecture of excitatory synapses: a more quantitative view. Annu Rev Biochem, 76, 823-847. doi: 10.1146/annurev.biochem.76.060805.160029

Sholl, D. A. (1953). Dendritic organization in the neurons of the visual and motor cortices of the cat. J Anat, 87(4), 387-406.

Soucek, S., Zeng, Y., Bellur, D. L., Bergkessel, M., Morris, K. J., Deng, Q., . . Corbett, A. H. (2016). The Evolutionarily-conserved Polyadenosine RNA Binding Protein, Nab2, Cooperates with Splicing Machinery to Regulate the Fate of pre-mRNA. Mol Cell Biol, 36(21), 2697-2714. doi: 10.1128/mcb.00402-16

Stein, I. S., \& Zito, K. (2019). Dendritic Spine Elimination: Molecular Mechanisms and Implications. Neuroscientist, 25(1), 27-47. doi: 10.1177/1073858418769644

Svoboda, K., Tank, D. W., \& Denk, W. (1996). Direct measurement of coupling between dendritic spines and shafts. Science, 272(5262), 716-719. doi: 10.1126/science.272.5262.716

Swanger, S. A., Yao, X., Gross, C., \& Bassell, G. J. (2011). Automated 4D analysis of dendritic spine morphology: applications to stimulus-induced spine remodeling and pharmacological rescue in a disease model. Molecular Brain, 4(1), 38. doi: 10.1186/1756-6606-4-38

Thelen, M. P., \& Kye, M. J. (2019). The Role of RNA Binding Proteins for Local mRNA Translation: Implications in Neurological Disorders. Front Mol Biosci, 6, 161. doi: 10.3389/fmolb.2019.00161

Thelen, M. P., \& Kye, M. J. (2020). The Role of RNA Binding Proteins for Local mRNA Translation: Implications in Neurological Disorders. Front Mol Biosci, 6(161). doi: 10.3389/fmolb.2019.00161

Wang, E. T., Taliaferro, J. M., Lee, J. A., Sudhakaran, I. P., Rossoll, W., Gross, C., . . Bassell, G. J. (2016). Dysregulation of mRNA Localization and Translation in Genetic Disease. J Neurosci, 36(45), 11418-11426. doi: 10.1523/jneurosci.2352-16.2016 
Wiedenmann, B., \& Franke, W. W. (1985). Identification and localization of synaptophysin, an integral membrane glycoprotein of Mr 38,000 characteristic of presynaptic vesicles. Cell, 41(3), 10171028. doi: 10.1016/s0092-8674(85)80082-9

Xavier, G. F., \& Costa, V. C. (2009). Dentate gyrus and spatial behaviour. Prog Neuropsychopharmacol Biol Psychiatry, 33(5), 762-773. doi: 10.1016/j.pnpbp.2009.03.036

Yuste, R. (2011). Dendritic spines and distributed circuits. Neuron, 71(5), 772-781. doi: 10.1016/j.neuron.2011.07.024

Zalfa, F., Achsel, T., \& Bagni, C. (2006). mRNPs, polysomes or granules: FMRP in neuronal protein synthesis. Curr Opin Neurobiol, 16(3), 265-269. doi: 10.1016/j.conb.2006.05.010

Zuo, Y., Yang, G., Kwon, E., \& Gan, W. B. (2005). Long-term sensory deprivation prevents dendritic spine loss in primary somatosensory cortex. Nature, 436(7048), 261-265. doi: 10.1038 /nature03715 


\section{Figure Legends}

FIGURE 1. Zc3h14 ${ }^{\Delta e \times 13 / \Delta e x 13}$ mice show decreased neuronal dendritic spines compared to control. A) Representative dentate gyrus granule neurons from postnatal day 7 (P7) Zc3h14 ${ }^{+/+}(+/+)$and

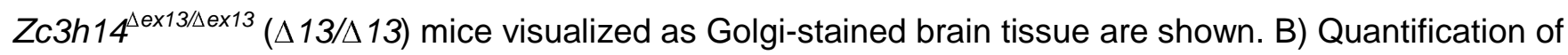
the number of dendritic spines per $10 \mu \mathrm{m}$, comparing $+/+$ and $\Delta 13 / \Delta 13$ mice at $\mathrm{P} 7$ from $(\mathrm{A})$. The total number of dendrites sampled is shown in the boxplots, with significance calculated by an unpaired $t$ test (NS: $p>0.05$ ). C) Representative dentate gyrus granule neuron of 5 month $+/+$ and $\Delta 13 / \Delta 13$ Golgistained brain tissue are shown. D) Quantification of the number of protrusions per $10 \mu \mathrm{m}$, comparing $+/+$ and $\Delta 13 / \Delta 13$ mice at 5 months from $(C)$. The number of dendrites sampled is shown in the boxplots, with statistical significance calculated by an unpaired $t$ test $\left({ }^{\star \star *} p<0.005\right)$.

FIGURE 2. Primary hippocampal neurons from $Z c 3 h 14^{\Delta e x 13 / \Delta e x 13}$ mice exhibit no significant difference in dendritic arborization at DIV12. A) Representative inverted immunofluorescence images of Zc3h14 ${ }^{+/+}$ $(+/+)$ and $Z c 3 h 14^{\Delta e x 13 / \Delta e x 13}(\Delta 13 / \Delta 13)$ primary hippocampal cells grown 12 days in vitro (DIV12). B-C) Quantification of total dendritic length and number of dendritic tips, respectively, comparing $+/+(\mathrm{n}=54)$ and $\Delta 13 / \Delta 13(n=54)$. Statistical significance was calculated by an unpaired $t$ test (NS: $p>0.05)$. D) Sholl analysis quantification between $+/+(n=51)$ and $\Delta 13 / \Delta 13(n=51)$ DIV12 primary hippocampal neurons, by number of dendritic intersections made with concentric sholl rings in $10 \mu \mathrm{m}$ increments, starting from the soma. Statistical significance was calculated by two-way ANOVA (NS: $p>0.05$ ).

FIGURE 3. Primary hippocampal neurons from Zc3h14 $4^{\Delta e x 13 / \Delta e x 13}$ mice cultured in vitro (DIV19) shows a statistically significant decrease in total dendritic spine density. A) Representative inverted fluorescence

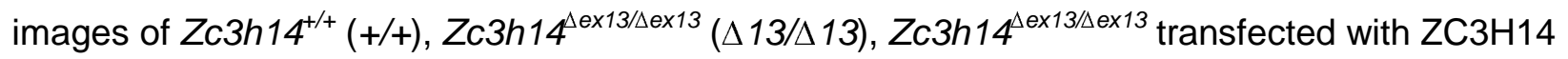

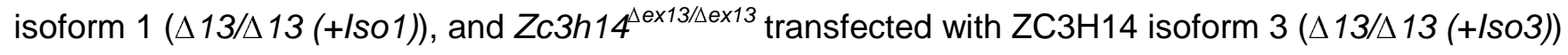
primary hippocampal neurons cultured for 19 days in vitro (DIV19). Cultured neurons were fluorescently labeled by LifeAct-mRuby transfection. Insets, 2.6X magnification. B) Quantification of the number of 
dendritic spines per $10 \mu \mathrm{m}$, comparing $+/+$ ( $\mathrm{n}=18$ neurons), $\Delta 13 / \Delta 13$ ( $\mathrm{n}=18$ neurons $), \Delta 13 / \Delta 13(+/$ so 1$)$ ( $\mathrm{n}=23$ neurons); and $\Delta 13 / \Delta 13$ (+lso3) ( $\mathrm{n}=19$ neurons) at DIV19. Statistical significance was calculated by an unpaired $t$ test $\left({ }^{*} p<0.05\right)$. C) A schematic of $\mathrm{ZC} 3 \mathrm{H} 14$ protein isoforms 1-4 (Iso1-4) with labeled domains (Leung et al., 2009) is shown: Proline-Tryptophan-Isoleucine (PWI)-like fold domain, Alternative N-terminus, predicted Nuclear Localization Sequence (NLS), and CysCysCysHis (CCCH) zinc finger (ZnF) RNA-binding domain.

FIGURE 4. Primary hippocampal neurons from Zc3h14 ${ }^{\Delta e x 13 / \Delta e x 13}$ mice cultured in vitro (DIV19) show a statistically significant decrease in mushroom-shaped dendritic spines that can be rescued by expressing $\mathrm{ZC} 3 \mathrm{H} 14$ Isoform 1 or 3 . A) A schematic illustrating the measurements used to classify "Stubby" (purple), "Thin" (light blue), and "Mushroom" (dark red) type dendritic spines, in terms of spine length, head width $(\mathrm{H}$, green), and neck width ( $\mathrm{N}$, red). B) Representative Imaris software

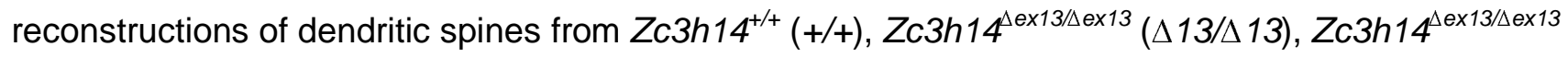
transfected with ZC3H14 isoform $1\left(\Delta 13 / \Delta 13\left(+\right.\right.$ Iso1)), and Zc3h14 ${ }^{\Delta e \times 13 / \Delta e \times 13}$ transfected with ZC3H14 isoform $3(\Delta 13 / \Delta 13(+$ lso3)), were constructed from fluorescent images of 19 days in vitro (DIV19) cultured primary hippocampal neurons. C) Quantification of the number of each spine type per $10 \mu \mathrm{m}$, comparing $+/+(\mathrm{n}=18$ neurons), $\Delta 13 / \Delta 13$ ( $\mathrm{n}=18$ neurons), $\Delta 13 / \Delta 13+(+/$ so 1$)$ ( $\mathrm{n}=23$ neurons); and $\Delta 13 / \Delta 13$ (+lso3) ( $n=19$ neurons). The color intensity for each box plot is used as a general comparative indicator for the level of functional $\mathrm{ZC} 3 \mathrm{H} 14$ protein present. Statistical significance was calculated by an unpaired $t$ test (NS: $p>0.05 ;{ }^{* *} p<0.01 ;{ }^{* *} p<0.001$ ).

FIGURE 5. Overexpression of ZC3H14 Isoform 1 in cultured primary hippocampal neurons (DIV19) increases dendritic spine density. A) Representative inverted fluorescence images of control primary Zc3h14 ${ }^{+/+}(+/+)$hippocampal neurons are shown together with Zc3h14 ${ }^{+/+}$primary hippocampal neurons transfected with $\mathrm{ZC} 3 \mathrm{H} 14$ Isoform $1(+/+(+$ Iso 1$))$ or ZC3H14 Isoform $3(+/+(+/$ so3 $))$. The primary hippocampal neurons were cultured for 19 days in vitro (DIV19). Cultured neurons were fluorescently 
labeled by LifeAct-mRuby transfection. Insets, 2.4X magnification. B) Quantification of the number of dendritic spines per $10 \mu \mathrm{m}$, comparing $+/+(\mathrm{n}=21$ neurons $),+/+(+l s o 1)(\mathrm{n}=14$ neurons $)$, and $+/+(+/$ so3 $)$ ( $\mathrm{n}=19$ neurons) at DIV19 is shown. Statistical significance was calculated by an unpaired $t$ test (NS>0.05; $\left.{ }^{* * *} p<0.0005\right)$.

FIGURE 6. The increase in spine density detected in DIV19 primary hippocampal neurons that overexpress $\mathrm{ZC} 3 \mathrm{H} 14$ Isoform 1 is due to an increase in the number of thin-type dendritic spines. A) Representative Imaris software reconstructions of dendritic spines from Zc3h14+/+ $(+/+)$ primary hippocampal neurons (control), Zc3h14 ${ }^{+/+}$neurons transfected with ZC $3 \mathrm{H} 14$ Isoform $1(+/+(+/$ so 1$))$, and $\mathrm{Zc} 3 h 14^{+/+}$neurons transfected with $\mathrm{ZC} 3 \mathrm{H} 14$ Isoform $3(+/+(+/$ so3 $))$, were constructed from fluorescent images of 19 days in vitro (DIV19) cultured primary hippocampal neurons. B) Quantification of the number of each spine type per $10 \mu \mathrm{m}$, comparing $+/+(\mathrm{n}=21$ neurons $),+/+(+/ s o 1)(\mathrm{n}=14$ neurons), and $+/+(+/ s o 3)$ ( $\mathrm{n}=19$ neurons) samples. Statistical significance was calculated by an unpaired $t$ test $\left(\mathrm{NS}>0.05 ;{ }^{* * *} \mathrm{p}<0.001\right)$.

FIGURE 7. ZC3H14 is present in synaptosomes and CaMKIla levels are increased in synaptosomal fractions from $Z c 3 h 14^{\Delta e \times 13 / \Delta e x 13}$ mice compared to control. A) A schematic illustrates the synaptosomal fractionation procedure, which produces fractions corresponding to total homogenate (Hom), cytosol (Cyt) and synaptosome (Syn) derived from a single postnatal day 0 (P0) whole mouse brain. B) Immunoblotting for synaptophysin (SYP, $\sim 38 \mathrm{kDa}$ ), in the Hom, Cyt, and Syn fractions from a Zc3h14 ${ }^{+/+}$ $(+/+)$ male whole mouse brain demonstrates the enrichment for this synaptic protein in the Syn fraction.

C) An immunoblot analysis of Hom, Cyt, and Syn fractions comparing $+/+$ and $Z c 3 h 14^{\Delta e \times 13 / \Delta e \times 13}$

$(\Delta 13 / \Delta 13)$ P0 whole mouse brain samples is shown. The top panel shows an immunoblot to detect ZC3H14, using an N-terminal antibody that detects Zc3H14 Isoforms 1 ( 100 kDa) and 2/3 ( 70 kDa) (Leung et al., 2009). The position of a truncated, nonfunctional ZC3H14 protein that is detected in the Zc3h14 $4^{\Delta e \times 13 / \Delta e x 13}$ mouse (Rha et al., 2017) is indicated by the *. D) Immunoblots shown compare the 
Syn fractions from $+/+$ and $\Delta 13 / \Delta 13 \mathrm{P} 0$ whole mouse brain samples. Panels show immunoblots for

ZC3H14, CaMKIla ( 50kDa), and postsynaptic density protein 95 (PSD-95, 95 kDa). The bottom panel shows total protein detected by Ponceau, which serves as a loading control. E) Quantification of CaMKIla and PSD-95 levels in the Syn fraction comparing $+/+(n=3)$ and $\Delta 13 / \Delta 13(n=3)$ where $\mathrm{n}=$ independent male mice. For each protein, the level of protein detected was set to 1.0 for the $+/+$ control and results are plotted as Relative to this control sample. Statistical significance was calculated by an unpaired $t$ test $\left(\mathrm{NS}>0.05 ;{ }^{*} p=0.04\right)$. 
Jones et. al Fig 1
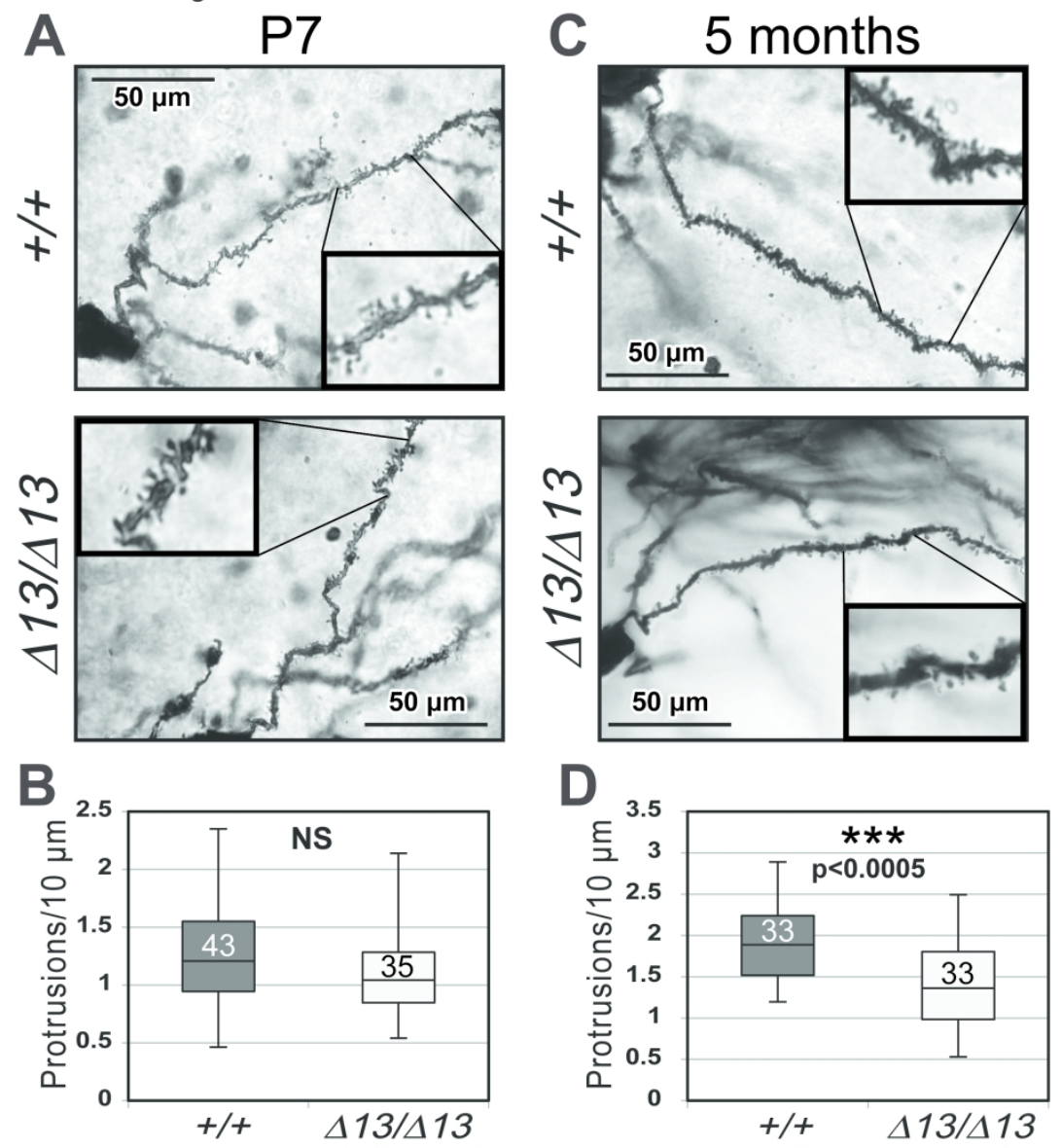

FIGURE 1. Zc3h14 4 ex13/4ex13 mice show decreased neuronal dendritic spines compared to control. 
Jones et. al Fig 2
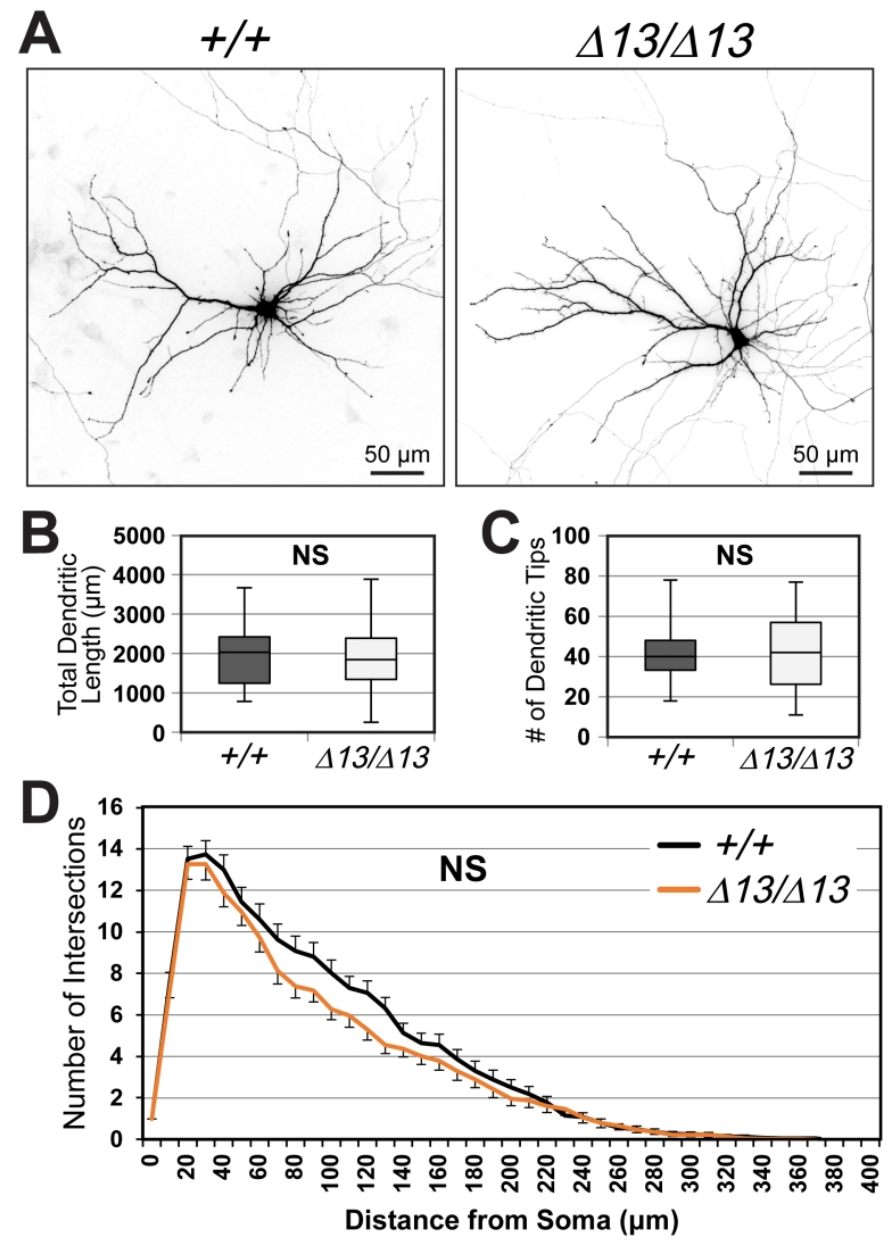

FIGURE 2. Primary hippocampal neurons from $Z c 3 h 14^{\Delta e x 13 / \Delta e \times 13}$ mice exhibit no significant difference in dendritic arborization at DIV12. 
Jones et. al Fig 3
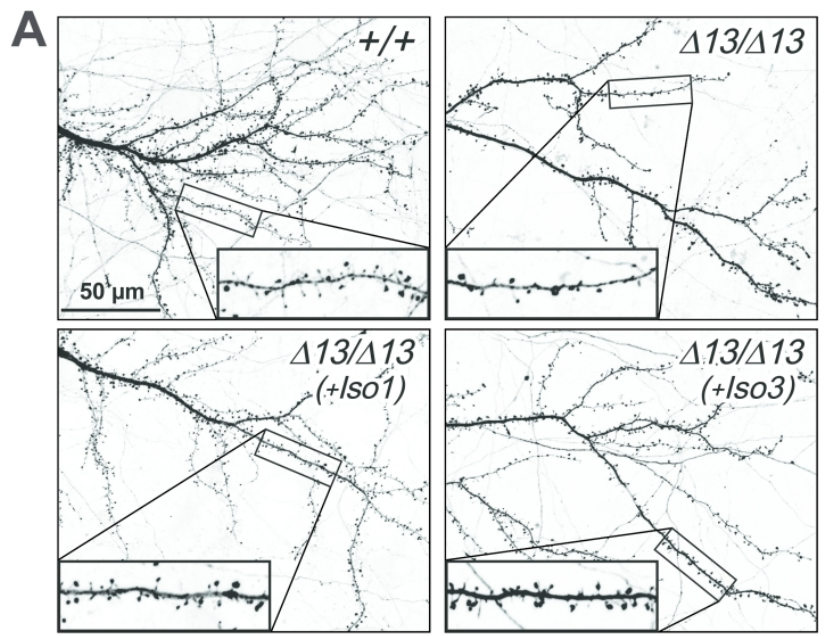

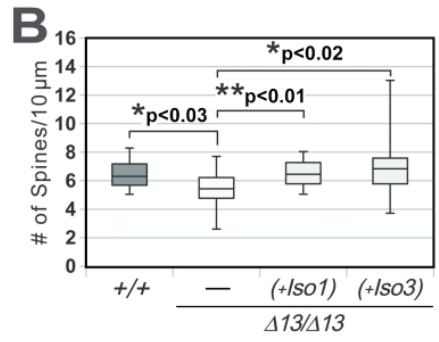

C zc3H14 Protein Isoforms

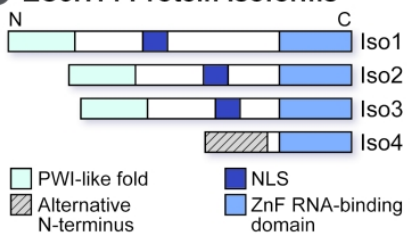

FIGURE 3. Primary hippocampal neurons from $Z c 3 h 14 \Delta^{e \times 13 / \Delta e \times 13}$ mice cultured in vitro (DIV19) shows a statistically significant decrease in total dendritic spine density. 
Jones et. al Fig 4
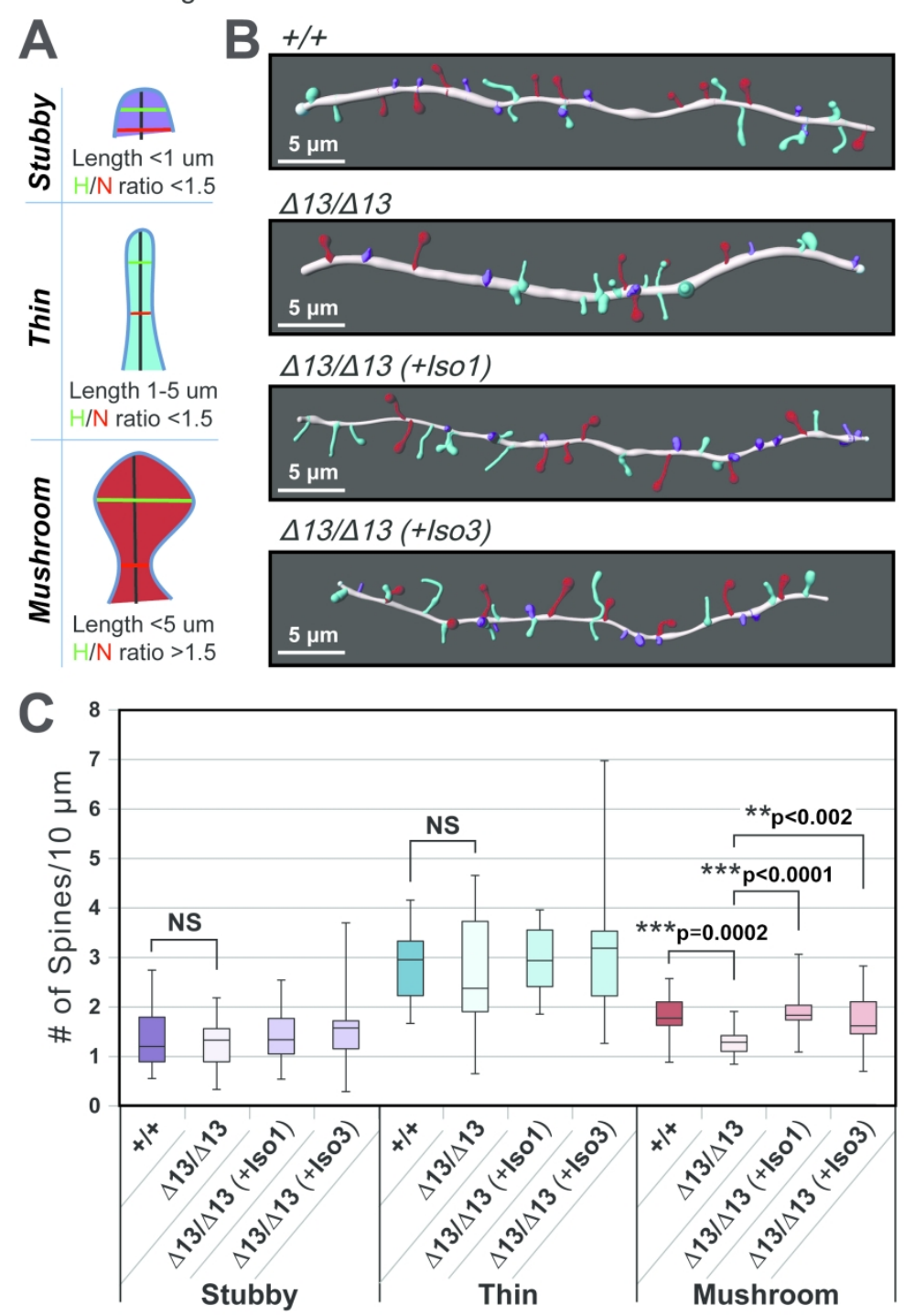

FIGURE 4. Primary hippocampal neurons from $Z c 3 h 14^{\Delta e x 13 / \Delta e x 13}$ mice cultured in vitro (DIV19) show a statistically significant decrease in mushroom-shaped dendritic spines that can be rescued by expressing ZC3H14 Isoform 1 or 3. 
Jones et. al Fig 5
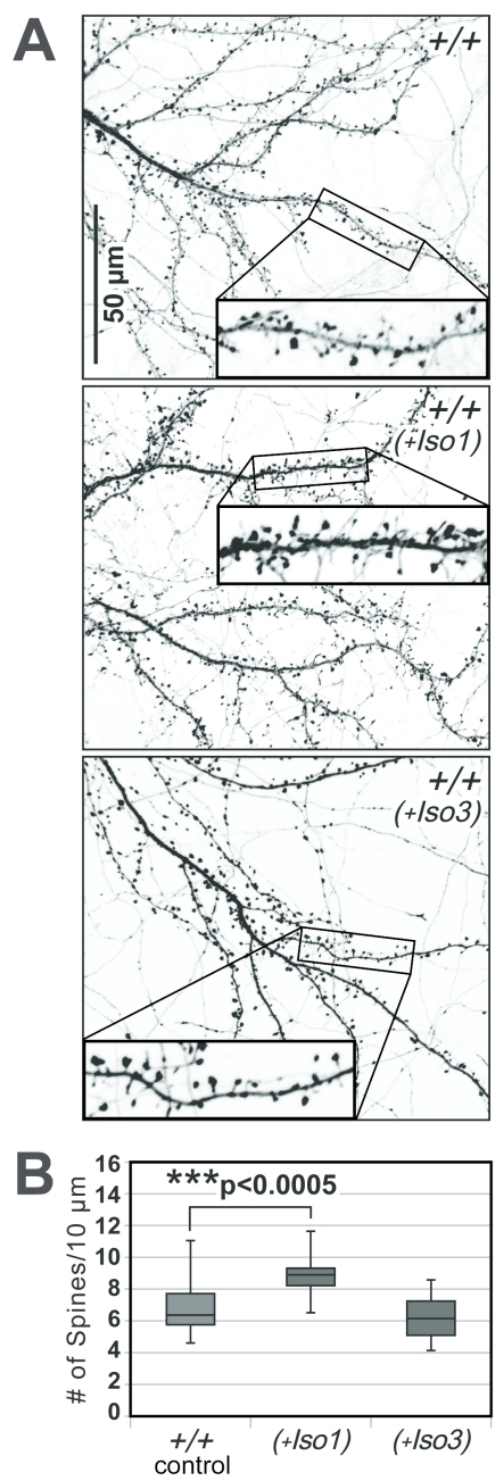

FIGURE 5. Overexpression of ZC3H14 Isoform 1 in cultured primary hippocampal neurons (DIV19) increases dendritic spine density. 
Jones et. al Fig 6

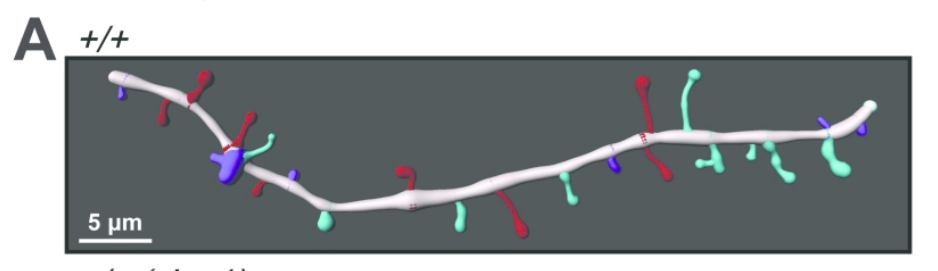

$+/+(+/ s 01)$

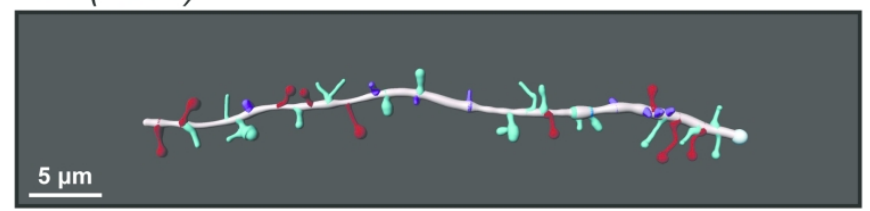

$+/+(+1 s 03)$

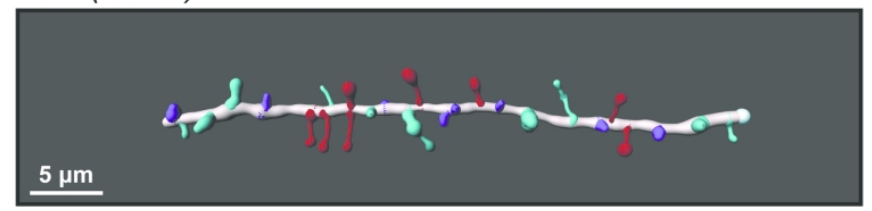

B

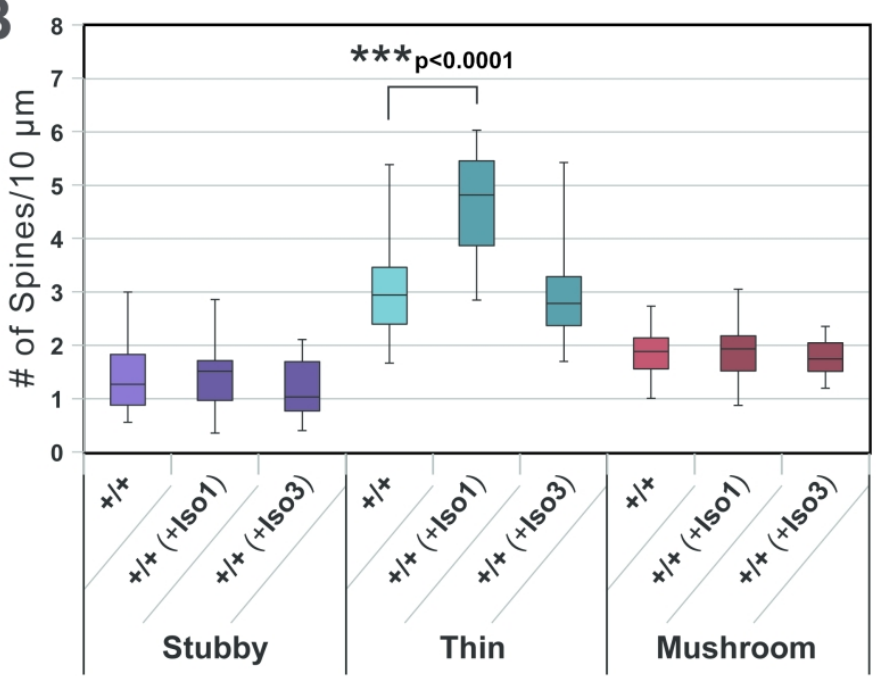

FIGURE 6. The increase in spine density detected in DIV19 primary hippocampal neurons that overexpress $\mathrm{ZC} 3 \mathrm{H} 14$ Isoform 1 is due to an increase in the number of thin-type dendritic spines. 


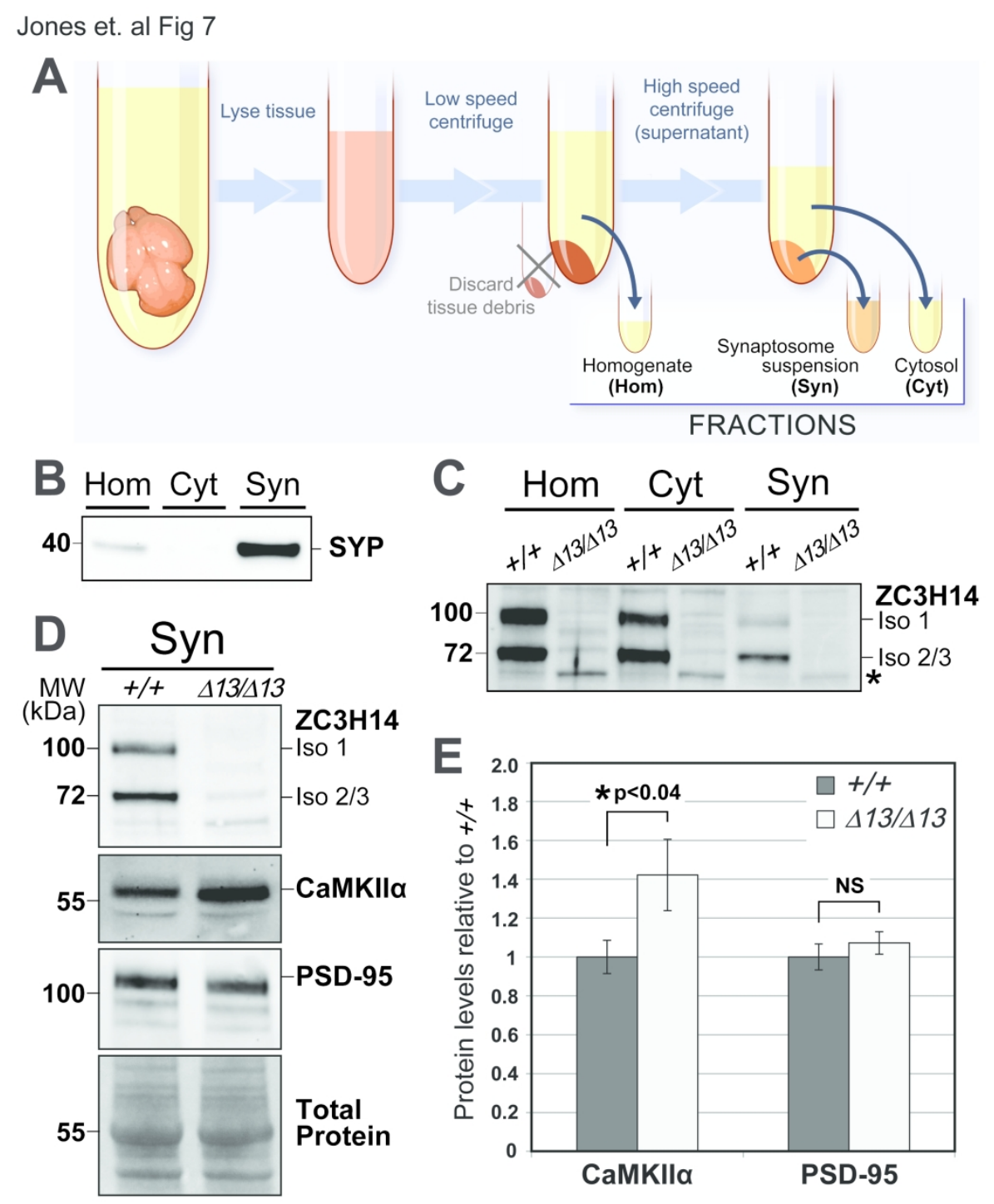

FIGURE 7. ZC3H14 is present in synaptosomes and CaMKIIa levels are increased in synaptosomal fractions from $Z c 3 h 14^{\Delta e x 13 / \Delta e x 13}$ mice compared to control. 